\author{
UNIVERSIDADE DE SÃO PAULO \\ FACULDADE DE MEDICINA DE RIBERÃO PRETO \\ PROGRAMA DE PÓS-GRADUAÇÃO EM FISIOLOGIA
}

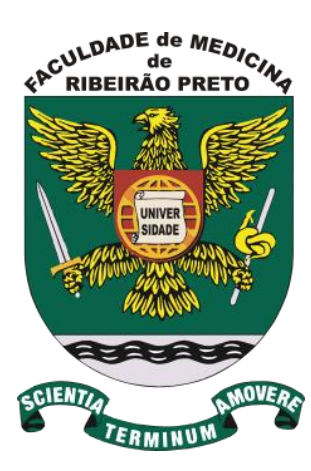

KARLA LIMA RODRIGUES

Caracterização das atividades autonômicas e respiratórias na preparação in situ de camundongos submetidos à hipóxia mantida

Ribeirão Preto - SP 
KARLA LIMA RODRIGUES

Caracterização das atividades autonômicas e respiratórias na preparação in situ de camundongos submetidos à hipóxia mantida

Dissertação de mestrado apresentada ao Programa de Pós-Graduação em Fisiologia da Faculdade de Medicina de Ribeirão Preto, Universidade de São Paulo, para a obtenção do título de Mestre em Ciências.

Área de concentração: Fisiologia

Orientador: Prof. Dr. Benedito H. Machado

Ribeirão Preto - SP 
Autorizo a reprodução e divulgação total ou parcial deste trabalho, por qualquer meio convencional ou eletrônico, para fins de estudo e pesquisa, desde que citada a fonte.

Rodrigues, Karla Lima

Caracterização das atividades autonômicas e respiratórias na preparação in situ de camundongos submetidos à hipóxia mantida. Ribeirão Preto: 2021. 77 p. : il. ; $30 \mathrm{~cm}$

Dissertação de Mestrado, apresentada à Faculdade de Medicina de Ribeirão Preto/USP. Área de concentração: Fisiologia.

Orientador: Machado, Benedito Honório.

1. Hipóxia. Camundongo. Resposta cardiovascular e respiratória. Quimiorreceptores. Expiração ativa. Atividade parassimpática. Atividade simpática. 
Nome: RODRIGUES, K.L.

Título: Caracterização das atividades autonômicas e respiratórias na preparação in situ de camundongos submetidos à hipóxia mantida

Dissertação de mestrado apresentada ao Programa de Pós-Graduação em Fisiologia da Faculdade de Medicina de Ribeirão Preto, Universidade de São Paulo, para a obtenção do título de Mestre em Ciências. Área de concentração: Fisiologia

Aprovada em:

\section{BANCA EXAMINADORA}

Prof. Dr. Benedito H. Machado (orientador)

Instituição: Faculdade de Medicina de Ribeirão Preto, Universidade de São Paulo Assinatura:

Prof. Dr.

Instituição:

Assinatura:

Prof. Dr.

Instituição

Assinatura: 
Dedico aos meus pais, Sônia Helena de Lima Rodrigues e Carlos Rodrigues da Silva e a minha avó Floracy Pereira de Lima, por absolutamente tudo! Sem vocês nada disso seria possível.

Ao meu irmão Júnio César de Lima Rodrigues, que independente da distância, sempre me apoiou.

Aos meus amigos, que independente das circunstâncias e/ou distância foram um apoio indispensável nesta trajetória.

Vocês me ensinaram que família, um lar, não depende de um lugar, mas sim das pessoas que nos amam. A vocês todo o meu amor e gratidão! 


\section{AGRADECIMENTOS}

Primeiramente, gostaria de agradecer a Deus e ao universo, por todas as oportunidades e pessoas que foram colocadas no meu caminho até aqui. Foram encontros, desencontros, escolhas e aprendizados. Experiências que construíram e que sempre serão parte da minha história, a tudo sou muito grata.

Aos meus pais, sem vocês nada disso seria possível! Todo seu amor e apoio, foram motivações para continuar a trilhar meu caminho longe de casa e persistir nos meus sonhos e objetivos. Agradeço por toda a paciência e carinho, por toda ajuda financeira ou pelas palavras de sabedoria. Vocês sempre estarão no meu coração aonde quer que eu vá!

A minha avó amada Floracy, a senhora é a personificação de bondade, amor e sabedoria. Uma segunda mãe, aquela sempre cuidou da nossa família e a razão pela qual somos unidos! Obrigada por tudo e por simplesmente ser a senhora. Serei eternamente grata!

Ao meu irmão, minha cunhada Andreza e afilhada Isabella (meu raio de sol, a florzinha mais linda de todo o campo). Vocês, mesmo de longe, são apoio, são suporte, são família. Obrigada por tudo!

Ao professor Bendito Machado, o senhor me deu a oportunidade de continuar trabalhando com pesquisa e a aprender com um dos melhores! Agradeço por todas as palavras de sabedoria, ensinamentos e, principalmente, paciência. Sua orientação foi primordial para a realização deste trabalho e para minha formação. Admiro sua pessoa e profissionalismo e que algum dia eu possa ser uma professora/pesquisadora tão eximia quanto o senhor.

Aos meus colegas, companheiros e amigos de laboratório Daniela Accorsi, Darlan, Juliana e Júlio, vocês são pessoas incríveis, cada um com seu jeitinho especial. Vocês me fizeram sentir acolhida desde o primeiro momento que cheguei em Ribeirão Preto. A Juliana e Darlan, um agradecimento especial pelas colaborações durante esse trabalho, foi um prazer trabalhar e aprender com vocês! Mas a todos, obrigada por tudo, os conselhos, conversas e momentos compartilhados! Quero levar a nossa amizade para a vida! 
Ao professor Davi e Melina, obrigada por toda ajuda, orientação e ensinamentos. Fico muito feliz por ter a oportunidade de aprender e colaborar com vocês. Agradeço a paciência e orientação nesta caminhada. Espero que possamos trabalhar muito juntos ainda, tenho muito a aprender com vocês.

Aos meus melhores amigos Romero e Andrielly, mesmo com a distância fizeram os dias tristes mais alegres. Em meio a tantas crises existenciais $e$ ansiedades me lembraram do por que trilhamos o nosso caminho e me apoiaram independente de qualquer coisa. Obrigada pelas madrugadas de conversas, pelas ajudas pessoais, emocionais ou até mesmo profissionais. Amo vocês!

A Daniela Siqueira, minha amiga, companheira de apartamento e de luta! Dani, nestes últimos 2 anos e meio, tudo que passamos juntas, só o apartamento 401 sabe. Você foi amiga, foi irmã... me aguentou em todos os momentos mais difíceis da pós graduação e durante uma pandemia. Você virou família! Uma garota tão pequena, mas que tem um coração maior que ela mesma, guerreira e resiliente. Você merece o mundo e todas as coisas boas que existem nele. Que todos os seus sonhos virem realidade e que um dia possamos estar sentadas em algum lugar de Paris ou Nova lorque tomando nosso café e relembrando de todos os perrengues que já passamos. Obrigada pela paciência, apoio e conselhos. Você foi a minha pessoa! Amo você!

A Marina e Rafael, vocês foram pessoas essenciais nestes últimos anos. Obrigada por todas as conversas, risadas e momentos compartilhados. Vocês fizeram parte do nosso G4 e da família do apto 401. Além disso, sempre compartilharam das mesmas angustias e perrengues de pós graduando. Espero levar essa amizade para a vida e que no futuro possamos estar em uma confraternização relembrando todos os nossos momentos que vivemos nesta época! Obrigada por tudo!

A todos os professores do Departamento e do Programa em Pós Graduação (PPG) em Fisiologia, foi uma honra poder conviver e aprender diretamente com todos aqueles que há alguns anos eu apenas admirava por livros e artigos científicos. Vocês são exemplos de profissionais! 
Aos servidores da secretária do PPG em Fisiologia, Elisa, Cláudia e Fernando, agradeço por todo auxilio e paciência. Sempre que precisei e me sentia perdida com as burocracias da pós vocês foram tão solícitos e gentis. Obrigada!

A todos os meus colegas e amigos que fiz na Pós graduação, vocês foram essenciais para compartilhar momentos felizes, de angustia ou de ansiedade. 0 caminho foi mais divertido e cheio de aprendizado ao lado de vocês, principalmente, durante o temido Cursão quando lá no começo sofremos para tentar absorver tanto conhecimento dos mestres. Obrigada por estarem ao meu lado!

A todos que estiveram diretamente e indiretamente relacionados a minha formação, profissional ou pessoal, meu obrigada de coração. Agradeço a todos aqueles que acreditaram em mim e no meu trabalho, meu sentimento é de gratidão! 
Gostaria de agradecer pelo investimento financeiro pela concessão de bolsa de mestrado. $O$ presente trabalho foi realizado com o apoio da Coordenação de Aperfeiçoamento de Pessoal de Nível Superior - Brasil (CAPES) - Código de Financiamento 001.

Á Fundação de Amparo à Pesquisa do Estado de São Paulo (FAPESP) e ao Conselho Nacional de Desenvolvimento Científico e Tecnológico (CNPq) pelo suporte financeiro, essencial para a realização deste trabalho.

Por fim, gostaria de agradecer ao Departamento de Fisiologia da Faculdade de Medicina de Ribeirão Preto por todo suporte estrutural indispensável para a realização deste trabalho. 
"A tarefa não é tanto ver aquilo que ninguém viu, mas pensar o que ninguém ainda pensou sobre aquilo que todo mundo vê." 


\section{RESUMO}

RODRIGUES, Karla Lima. Caracterização das atividades autonômicas e respiratórias na preparação in situ de camundongos submetidos à hipóxia mantida. 2021. 77 f. Dissertação (Mestrado em Fisiologia) - Faculdade de Medicina de Ribeirão Preto, Universidade de São Paulo, Ribeirão Preto/SP, 2021.

A hipóxia sustentada (HM) em ratos induz excitação simpática e hipertensão devido às alterações no acoplamento simpático-respiratório. No entanto, não há dados consistentes sobre o efeito da $\mathrm{HM}$ em camundongos devido aos diferentes protocolos de hipóxia e às dificuldades associadas ao manuseio desses roedores em diferentes condições experimentais. Além disso, registros na preparação in situ de nervos autonômicos e respiratórios em camundongos HM ainda não foram realizados. Nesse contexto, no presente estudo nós avaliamos os padrões cardiovasculares e respiratórios de camundongos submetidos ao protocolo de HM, bem como as respostas cardiovasculares desses roedores à ativação do quimiorreflexo. Camundongos C57BL/6J (7 - 8 semanas, 22g) foram submetidos ao protocolo controle (normóxia) ou $\mathrm{HM}\left(24 \mathrm{~h}, \mathrm{FiO}_{2}\right.$ 0,1 - 10\%). Ao final do protocolo de $\mathrm{HM}$ ou controle, os camundongos foram profundamente anestesiados com isoflurano, seccionados subdiafragmaticamente, exsanguinados, eviscerados e descerebrados pré-coliculamente. Os camundongos foram então colocados em uma câmara de registro para a preparação coração tronco encefálico isolados (WHBP) e a aorta descendente foi cateterizada e perfundida com aCSF. Esse cateter também foi usado para registrar a pressão de perfusão. Além disso, os nervos frênico (PN), abdominal, ( $\mathrm{AbN}$ ), vago cervical (cVN) e simpático torácico (tSN) foram dissecados e suas atividades foram registradas usando um eletrodo de vidro bipolar. Os resultados mostraram que a frequência basal de disparo do NF (DNF) foi significativamente reduzida em camundongos $\operatorname{HM}(n=11)$ em relação aos camundongos do grupo controle $[n=26(0,69 \pm 0,06$ vs $1,13 \pm 0,10 \mathrm{~Hz}, P=0,0154)]$. A incidência de expirações ativas (Late-E) na atividade $A b N$ em camundongos $H M$ $(n=10)$ foi significativamente aumentada em relação ao grupo controle $[n=20,(83,3 \pm$ $7,7$ vs $24,3 \pm 8,0 \%, P<0,0001)$ ]. A duração da expiração em camundongos $H M$ $(n=11)$ foi maior do que no grupo controle $[n=22,(1,13 \pm 0,16$ vs $0,67 \pm 0,07 s$, $P=0,0002)$ ] devido a um aumento na duração da pós-inspiração $(0,78 \pm 0,12$ vs 0,35 
$\pm 0,04 \mathrm{~s}, P=0,0032)$ e pré-inspiração $(0,26 \pm 0,12$ vs $0,08 \pm 0,02 s, P=0,0432)$. A atividade do tSN no grupo HM $(n=10)$ foi significativamente reduzida durante a expiração final (E2) em comparação com o grupo controle $(n=16)(19,0 \pm 4,3$ vs 39,7 $\pm 4,2 \%, P=0,0203)$. Os nossos resultados indicam que no protocolo de $\mathrm{HM}$ de $24 \mathrm{~h}$, os camundongos apresentam expiração ativa e fase expiratória mais longa na WHBP. Além disso, mudanças no padrão respiratório foram associadas a um aumento do tônus parassimpático e redução da atividade simpática na fase E2 do ciclo respiratório. Esse desequilíbrio autonômico favorece o componente parassimpático o que pode explicar por que camundongos não desenvolvem hipertensão em resposta à HM.

Palavras-chave: hipóxia; camundongo; resposta cardiovascular e respiratória; quimiorreceptores; expiração ativa; atividade parassimpática; atividade simpática; 


\section{ABSTRACT}

RODRIGUES, Karla Lima. Autonomic and respiratory profiles of mice in in situ preparation submitted to short-term sustained hypoxia. 2021. 77 p. Dissertation (Master in Physiology) - Ribeirão Preto Medical School, University of São Paulo, Ribeirão Preto, State of São Paulo, 2021.

Short-term sustained hypoxia $(\mathrm{SH})$ in rats induces sympathetic overactivity and hypertension due to changes in the sympathetic-respiratory coupling. However, there is no consistent data about the effect of $\mathrm{SH}$ on mice due to the different protocols of hypoxia and difficulties associated with the handling of these rodents under different experimental conditions. In situ recordings of autonomic and respiratory nerves in SH mice have not been performed yet. C57BL/6J mice (7-8 weeks old, $\sim 22 \mathrm{~g}$ ) were submitted to control (normoxia) or SH protocol (24h, $\left.\mathrm{FiO}_{2} 0.1-10 \%\right)$. At the end of $\mathrm{SH}$ or control protocol, mice were deeply anesthetized with Isoflurane, sectioned subdiaphragmatically, exsanguinated, eviscerated and decerebrated precollicularly. Mice were then placed into a recording chamber for the in situ working heart-brainstem preparation (WHBP), in which the descending aorta was catheterized and perfused with ACSF. This catheter was also used to record the perfusion pressure. In addition, phrenic (PN), abdominal, (AbN), cervical vagus (cVN) and thoracic sympathetic (tSN) nerves were dissected and their activities were recorded using bipolar glass electrode. We observed, that the baseline PN discharge (PND) frequency was significantly reduced in SH mice $(n=11)$ in relation to the control group $[n=26,(0.69 \pm$ 0.06 vs $1.13 \pm 0.10 \mathrm{~Hz}, P=0.0154)$ ]. The incidence of Late-E bursts in AbN activity in SH mice $(n=10)$ was significantly increased in relation to control group $[n=20,(83.3 \pm$ 7.7 vs $24.3 \pm 8.0 \%, P<0.0001)$ ]. The duration of expiration in $\mathrm{SH}$ mice $(n=11)$ was longer than in control group $[\mathrm{n}=22,(1.13 \pm 0.16$ vs $0.67 \pm 0.07 \mathrm{~s}, \mathrm{P}=0.0002)]$ due to an increase in the duration of post-inspiration $(0.78 \pm 0.12$ vs $0.35 \pm 0.04 \mathrm{~s}$, $\mathrm{P}=0.0032)$ and pre inspiration $(0.26 \pm 0.12$ vs $0.08 \pm 0.02 \mathrm{~s}, \mathrm{P}=0.0432)$. tSNA in the $\mathrm{SH}$ group $(\mathrm{n}=10)$ was significantly reduced during late-expiration (E2) compared with the control group $[n=16,(19.0 \pm 4.3$ vs $39.7 \pm 4.2 \%, P=0.0203)]$. The data are showing that in response to 24-h SH protocol, mice presented active expiration and longer expiratory phase in the WHBP. Furthermore, the changes in the respiratory pattern were associated with an increase in parasympathetic tone and reduction in 
the sympathetic activity in the E2 phase of the respiratory cycle. This autonomic imbalance favoring the parasympathetic component may explain why mice do not develop hypertension after $\mathrm{SH}$.

Keywords: hypoxia; mice; cardiovascular and respiratory responses; chemoreceptors; active expiration, parasympathetic activity, sympathetic activity. 


\section{LISTA DE FIGURAS}

Figura 1: Representação esquemática dos núcleos pontinos e bulbares responsáveis pelo controle autonômico e respiratório e suas respostas à ativação do quimiorreflexo periférico. A diminuição na pressão parcial de oxigênio do sangue arterial $\left(\mathrm{PaO}_{2}\right)$ ativa os quimiorreceptores periféricos, localizados no corpúsculo carotídeo, levando a despolarização de neurônios aferentes que levam essa informação da periferia até o NTS. Os neurônios aferentes provenientes dos quimiorreceptores periféricos realizam sua primeira sinapse com neurônios de segunda ordem no NTS. Os neurônios de ordem superior do NTS enviam projeções para os neurônios pré-motores simpáticos do RVLM, neurônios pré-ganglionares parassimpático do NA e para neurônios do VRG. Em conjunto, essas regiões e núcleos do tronco encefálico promovem respostas cardiovasculares e respiratórias integradas as quais são caracterizadas por intensa bradicardia, simpatoexcitação (a qual promove vasoconstrição e aumento da força de contração do coração), taquipneia e um aumento da atividade dos músculos abdominais (expiração ativa ou Late-E). rNTS: núcleo do trato solitário rostral; iNTS: núcleo do trato solitário intermediário; cNTS: núcleo do trato solitário caudal; PBN: núcleo parabraquial; KF: núcleo do fuso de Kölliker; SO: oliva superior; 7: núcleo facial; nRT: núcleo retrotrapezóide; NA: núcleo ambíguo; RVLM: medula ventro-lateral rostral; CVLM: medula ventro-lateral caudal; BötC: complexo de Bötzinger; Pré-BötC: complexo pré-Bötzinger; rVRG: grupamento respiratório ventral rostral; cVRG: grupamento respiratório ventral caudal; VRC: coluna respiratória ventral; LRt: núcleo reticular lateral; IML: coluna intermédio lateral.

Figura 2: Representação esquemática da preparação in situ coração-tronco encefálico isolados (Modificado de Moraes et al, 2015), mostrando os registros dos nervos vago cervical (cVN), simpático torácico (tSN), abdominal ( $\mathrm{AbN})$ e frênico $(\mathrm{PN})$.

Figura 3: Esquema representativo do protocolo experimental utilizado para estímulo do quimiorreflexo periférico.

Figura 4: Esquema representativo da divisão das fases do ciclo respiratório de camundongos submetidos a preparação in situ coração tronco encefálico isolados. Camundongos apresentaram um ciclo respiratório de quatro fases: Pré-inspiratória (pré-I), Inspiratório (Insp), pósinspiratória (Pós-I) e expiração final (E2). Em conjunto, as fases Pós-I e E2 compõem a expiração total, as quais são determinadas pela correlação da atividade do nervo vago cervical (cVN) e atividade do nervo frênico (PN).

Figura 5: Traçados representativos dos registros da frequência cardíaca e dos registros dos nervos autonômicos e respiratórios basais na preparação in situ de camundongos controle e HM. Traçados representativos de preparações in situ de um camundongo controle (painel A) e um camundongo HM (painel B) mostrando a frequência cardíaca basal (FC), e atividades bruta e integrada $\left(\int\right)$ dos nervos simpático torácico (tSN), nervo abdominal $(\mathrm{AbN})$ nervo vago cervical $(\mathrm{cVN})$ e nervo frênico (NF). A linha tracejada marca o início da fase Pré-I, a qual termina no começo da atividade em burst do NF. Insp: inspiratório, Pós-I: primeiro estágio da expiração, E2: segundo estágio da expiração. As setas indicam os eventos Late-E na atividade AbN. 
Figura 6: Valores médios da frequência cardíaca e dos parâmetros respiratórios na preparação in situ de camundongos controle e HM. Frequência cardíaca basal (FC, painel $A$ ) do grupo controle $(n=12)$ e HM $(n=10)$. Frequência da atividade de disparo do nervo frênico (DNF, painel $B)$ de camundongos do grupo controle $(n=23)$ e HM $(n=11)$. Incidência de eventos Late- $E$ na atividade do nervo abdominal (painel C) de camundongos controle $(n=20)$ e HM $(n=11)$. Duração das fases do ciclo respiratório (painéis $D$ e E) de camundongos controle $(n=22)$ e HM $(n=11)$. Insp: Inspiração, Exp: expiração total, Pós-I: primeiro estágio da expiração, E2: segundo estágio da expiração e Pré-I: préinspiração. * Diferente entre fases do mesmo grupo. \# diferente em relação ao grupo controle $(p<0,05)$. Teste t não pareado (painel $A-C$ ) e ANOVA de uma via para comparar fases no mesmo grupo e ANOVA de duas vias para comparar as diferenças entre os grupos (painéis $D$ e E).

Figura 7: Valores médios da atividade dos nervos vago cervical e simpático torácico durante as fases do ciclo respiratório na preparação in situ de camundongos do grupo controle e HM. Atividade basal do nervo vago cervical $[(\% \mathrm{cVN}$, painel $A$, camundongos do grupo controle $(n=21)$ e HM $(n=11)$ ] e atividade basal do nervo simpático torácico [(\%tSNA, painel $B$, camundongos do grupo controle $(n=16)$ e HM $(n=10)$ ] durante a fase inspiratória (Insp), post-inspiração (Pós-I) e expiração final (E2) dos grupos controle e HM (painel A). * Diferente entre fases do mesmo grupo. \# diferente em relação ao grupo controle $(p<0,05)$. ANOVA de uma via para comparar fases no mesmo grupo e ANOVA de duas vias para comparar as diferenças entre os grupos.

Figura 8: Traçados representativos dos registros da frequência cardíaca e dos registros dos nervos autonômicos e respiratórios na preparação in situ de camundongos controle e HM durante o estímulo do quimiorreflexo periférico. Traçados representativos de preparações in situ de um camundongo controle (painel A) e um camundongo HM (painel B) mostrando a frequência cardíaca basal (FC), e atividades bruta e integrada ( $(\delta)$ dos nervos simpático torácico (tSN), nervo abdominal $(\mathrm{AbN})$ e nervo frênico (NF). A linha tracejada vermelha marca o momento da injeção de $\mathrm{KCN}(20 \mu \mathrm{g} / 50 \mu \mathrm{L})$.

Figura 9: Valores médios das respostas de bradicardia, autonômica simpática e respiratórias em resposta à ativação ao quimiorreflexo periférico na preparação in situ do grupo controle e $H M$. Alterações na frequência cardíaca $(\triangle F C$, painel $A)$ de camundongos do grupo controle $(n=12)$ e HM $(n=10)$. Atividade do nervo torácico simpático (tSNA, $\Delta \%$, painel B) de camundongos do grupo controle $(n=15)$ e HM $(n=9)$ em resposta a ativação do quimiorreflexo periférico. Frequência de disparo do nervo frênico (DNF, Hz, painel C) de camundongos do grupo controle ( $n=20)$ e HM $(n=11)$ em resposta a ativação do quimiorreflexo periférico. Atividade do nervo abdominal (Abd, \%, painel D) de camundongos do grupo controle $(n=17)$ e $\mathrm{HM}(n=9)$ em resposta a ativação do quimiorreflexo periférico. Comparação estatística feita por meio do teste t de Student não pareado). 


\section{LISTA DE ABREVIATURAS E SIGLAS}

Núcleo facial

AbN Nervo abdominal

aCFS Fluído cerebroespinhal artificial modificado

AOS Apnéia obstrutiva do sono

ATP Adenosina trifosfato

BötC Complexo Bötzinger

bpm Batimentos por minuto

CEUA Comissão de ética no uso de animais na experimentação

cNTS Núcleo do trato solitário caudal

cNV Nervo vago cervical

CVLM Medula ventro-lateral caudal

cVRG Grupamento respiratório ventral caudal

DNF Disparos do nervo frênico

DP

Desvio padrão

E2 Expiração final

FC Frequência cardíaca

$\mathrm{FiO}_{2} \quad$ Fração inspirada de oxigênio

FMRP Faculdade de medicina de Ribeirão Preto

$f_{R} \quad$ Frequência respiratória

$\mathrm{HCl} \quad$ Hipóxia crônica intermitente

HM Hipóxia mantida

IML Coluna intermédio lateral

Insp Inspiratório

iNTS Núcleo do trato solitário intermediário

KCN Cianeto de potássio

KF Núcleo do fuso de Kölliker

Late-E Expiração ativa

LRt Núcleo reticular lateral 


$\begin{array}{ll}\text { mmHg } & \text { Milímetros de mercúrio } \\ \text { NA } & \text { Núcleo ambíguos } \\ \text { NF } & \text { Nervo frênico } \\ \text { nRT } & \text { Núcleo retro-trapezóide } \\ \text { NTS } & \text { Núcleo do trato solitário } \\ \text { PaO2 } & \text { Pressão parcial de oxigênio } \\ \text { PBN } & \text { Núcleo parabraquial } \\ \text { pFRG } & \text { Grupo respiratório parafacial } \\ \text { Pós-I } & \text { Pós-inspiratório } \\ \text { PP } & \text { Pressão de perfusão } \\ \text { Pré-BötC } & \text { Complexo pré-Bötzinger } \\ \text { Pré-I } & \text { Pré-inspiratório } \\ \text { rNTS } & \text { Núcleo do trato solitário rostral } \\ \text { RVLM } & \text { Medula ventro-lateral rostral } \\ \text { rVRG } & \text { Grupamento respiratório ventral rostral } \\ \text { SNC } & \text { Sistema nervoso central } \\ \text { SO } & \text { Oliva superior } \\ \text { tANS } & \text { Atividade do nervo eferente simpático torácico } \\ \text { tSN } & \text { Nervo simpático torácico } \\ \text { USP } & \text { Universidade de São Paulo } \\ \text { VE } & \text { Ventilação pulmonar } \\ \text { VRC } & \text { Coluna respiratória ventral } \\ \text { WHBP } & \text { Preparação in situ coração-tronco encefálico isolados }\end{array}$




\section{LISTA DE SIMBOLOS}

\begin{tabular}{|c|c|}
\hline \# & Diferente em relação ao grupo controle \\
\hline$\%$ & Porcentagem \\
\hline$\mu \mathrm{m}$ & Micrômetro \\
\hline * & Diferente entre fases do mesmo grupo \\
\hline$=$ & lgual \\
\hline \pm & Mais ou menos \\
\hline $\int$ & Integral \\
\hline$\leq$ & Menor ou igual \\
\hline${ }^{\circ} \mathrm{C}$ & Graus Celsius \\
\hline$\mu g$ & Microgramas \\
\hline$\mu \mathrm{L}$ & Microlitros \\
\hline$\mu \mathrm{V}$ & Microvolt \\
\hline $\mathrm{CaCl}_{2}$ & Cloreto de Cálcio \\
\hline $\mathrm{cm}$ & Centímetros \\
\hline $\mathrm{CO}_{2}$ & Dióxido de carbono \\
\hline$g$ & Gramas \\
\hline $\mathrm{h}$ & Horas \\
\hline $\mathrm{Hz}$ & Hertz \\
\hline $\mathrm{KCl}$ & Cloreto de Potássio \\
\hline $\mathrm{KH}_{2} \mathrm{PO}_{4}$ & Fosfato monopotássico \\
\hline $\mathrm{kHz}$ & Kilohertz \\
\hline $\mathrm{L}$ & Litros \\
\hline $\mathrm{MgSO}_{4}$ & Sulfato de magnésio \\
\hline $\min ^{-1}$ & Por minuto \\
\hline $\mathrm{ml}$ & Mililitro \\
\hline $\mathrm{mm}$ & Milímetro \\
\hline $\mathrm{mM}$ & Milimolar \\
\hline ms & Milissegundos \\
\hline
\end{tabular}




$\begin{array}{ll}\mathrm{N}_{2} & \text { Gás Nitrogênio } \\ \mathrm{NaCl} & \text { Cloreto de sódio } \\ \mathrm{NaHCO}_{3} & \text { Bicarbonato de sódio } \\ \mathrm{nM} & \text { Nanomolar } \\ \mathrm{O}_{2} & \text { Oxigênio } \\ \mathrm{pH} & \text { Potencial hidrogeniônico } \\ \mathrm{s} & \text { Segundos } \\ \text { vs } & \text { versus } \\ \Delta & \text { Variação }\end{array}$




\section{Sumário}

1. INTRODUÇÃO .23

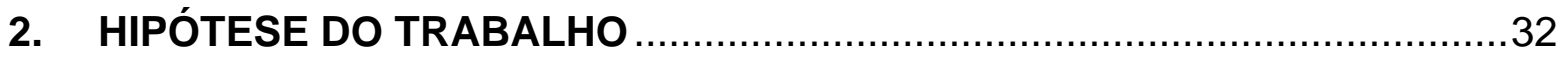

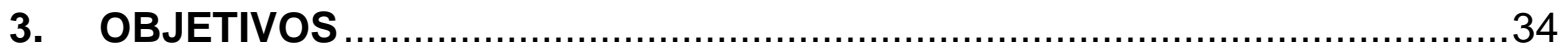

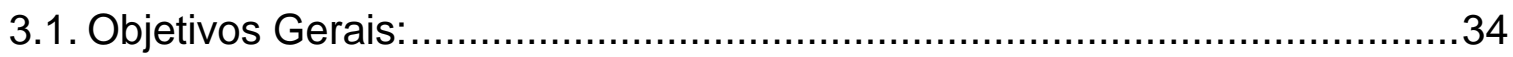

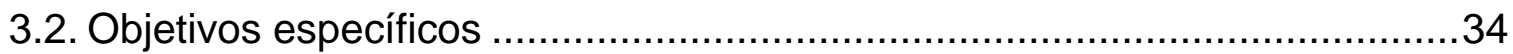

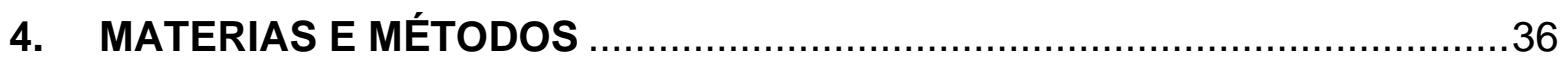

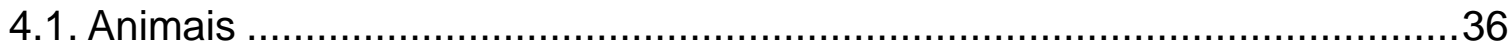

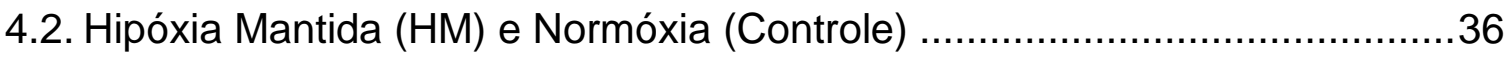

4.3. Experimentos com a preparação in situ coração tronco encefálico isolados

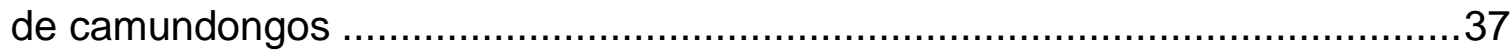

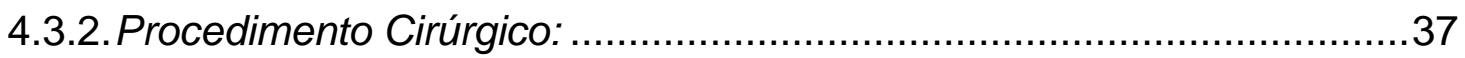

4.3.3. Registros da frequência cardíaca e das atividades dos nervos frênico, simpático torácico, vago cervical e abdominal na preparação in situ coração

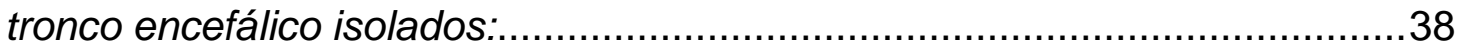

4.3.4.Ativação do quimiorreflexo periférico na preparação in situ coração

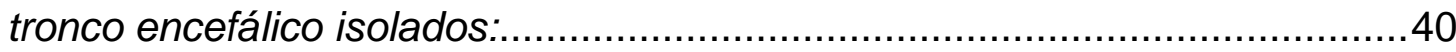

4.4. Protocolos experimentais na preparação in situ...........................................40

4.5. Análise dos resultados obtidos por meio dos registros neurais na preparação

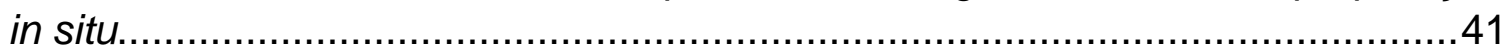

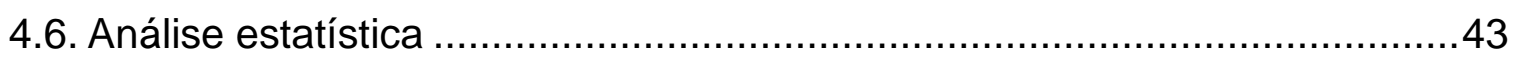

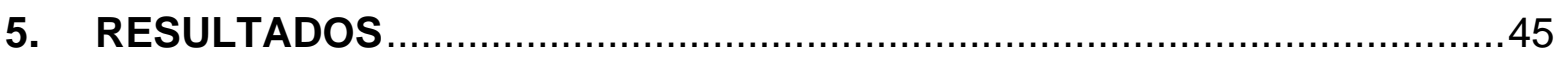

5.1. Parâmetros respiratórios, cardiovasculares e autonômicos basais na preparação in situ de camundongos controle e HM

5.2. Parâmetros respiratórios na preparação in situ de camundongos controle e HM 46

5.3. Atividades basais dos nervos vago cervical e simpático torácico na preparação in situ de camundongos controle e HM.

5.4. Bradicardia e simpato-excitação em resposta à ativação do quimiorreflexo periférico na preparação in situ de camundongos controle e HM .......................50

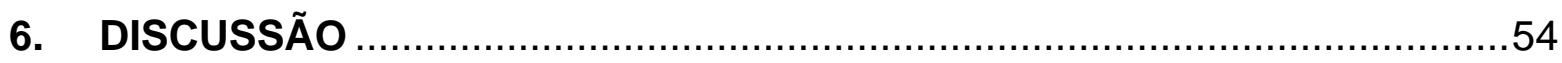

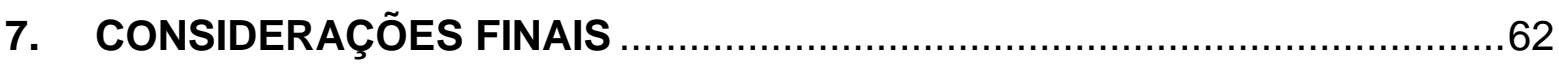

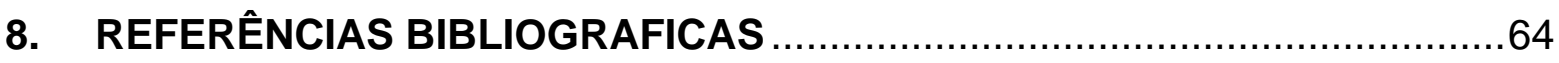

Apêndice I

Artigo publicado referente à pesquisa desenvolvida nesta dissertação

Apêndice II

Artigo publicado relacionado ao período de realização do mestrado 
Introdução 


\section{INTRODUÇÃO}

Independente da diversidade dos órgãos e células, um organismo tem como objetivo principal manter o meio interno estável em relação ao meio externo, promovendo desta forma o equilíbrio de todas as funções necessárias à sobrevivência do mesmo (CANNON, 1929; RODOLFO, 2000; COOPER, 2008; TORDAY, 2015; MODELL et al, 2015, PALAPARTHI, 2017). Assim, a homeostase corporal foi conceituada como sendo a manutenção das condições do meio interno, no qual todos os processos fisiológicos terão este equilíbrio como finalidade. (CANNON, 1929; RODOLFO, 2000; COOPER, 2008; PALAPARTHI, 2017).

Neste sentido, uma das funções mais importantes do sistema nervoso central (SNC), do ponto de vista evolutivo, é a coordenação integrada de todos os sistemas fisiológicos, tanto sob condições ambientais normais ou condições de desafios fisiológicos (COSTA et al., 2014). Entre esses sistemas, merecem destaque o respiratório e o cardiovascular, os quais, nos vertebrados superiores, atuam em conjunto para captar o oxigênio do ar atmosférico e distribuí-lo juntamente com outros diversos nutrientes por meio do aporte sanguíneo para todas as células do organismo, principalmente para o cérebro e o coração (ABBOUD et al., 1976; ZOCCAL et al., 2009; MOREIRA et al., 2011; COSTA et al., 2014). Essa função cardiovascular e respiratória, essencial para a manutenção da vida, é regulada principalmente por núcleos pontinos e bulbares no SNC (FELDMAN \& MCCRIMMON, 2008).

Dentre as regiões responsáveis pela geração e modulação da atividade autonômica para o sistema cardiovascular, merecem destaque os grupamentos neuronais localizados nos aspectos ventrais da medula (RVLM, Figura 1), que concentram circuitos que geram e regulam a atividade simpática (PADLEY et al., 2007), influenciando assim a função cardiovascular (MIFFLIN, 1992). Nesta modulação há o envolvimento de diversos mecanismos, os quais tem como objetivo promover um maior fluxo sanguíneo para os órgãos e tecidos em atividade, e também realizam uma redistribuição do sangue frente a perturbações na homeostasia (SMITH, 1974). O SNC participa do controle do sistema cardiovascular por meio de ajustes rápidos nas atividades eferentes simpática e parassimpática, os quais promovem ajustes na pressão arterial e na frequência cardíaca (MANCIA et 
al., 1985; KARA et al., 2003). Esses ajustes envolvem a participação de sensores periféricos, os quais transmitem as informações captadas para regiões específicas do SNC envolvidas com o controle da atividade autonômica (MACHADO, 2001). Dentre os mecanismos neurais mais importantes para o controle da função cardiovascular e respiratória, destacam-se o barorreflexo e o quimiorreflexo periférico (MACHADO, 2001).

Os quimiorreceptores periféricos são estruturas especializadas em detectar as alterações na pressão parcial de oxigênio do sangue arterial $\left(\mathrm{PaO}_{2}\right)$ e estão localizados, principalmente, nos corpúsculos carotídeos (BISCOE \& DUCHER, 1990). Em situações de hipóxia, esses quimiorreceptores são estimulados e os potenciais de ação gerados se propagam, por meio do nervo do seio carotídeo, em direção ao núcleo do trato solitário [(NTS) Figura 1], desencadeando respostas autonômicas para o sistema cardiovascular (ROSS et al, 1985; URBANSKI \& SAPRU, 1988; GRANATA,1994; AICHER et al., 1996; BARROS et al., 2002) e também respostas ventilatórias. No NTS estão localizadas as primeiras sinapses das aferências dos quimiorreceptores periféricos. Em situações de hipóxia os quimiorreceptores periféricos são ativados e, ao enviarem informações ao NTS, dão início ao chamado quimiorreflexo periférico. Na ativação desse reflexo, se destaca um pronunciado aumento da pressão arterial (excitação simpática), intensa bradicardia (excitação parassimpática), aumento da frequência respiratória [(resposta dos núcleos respiratórios) Figura 1] e uma resposta comportamental de exploração do ambiente (FRANCHINI \& KRIEGER, 1993; BARROS et al., 2002). Com relação à modulação respiratória, merece destaque os grupamentos neuronais localizados na coluna respiratória ventral (VRC, Figura 1), como o complexo préBötzinger (pré-BötC) e Bötzinger [(BötC) Figura 1], que são as principais regiões nas quais se encontram os neurônios responsáveis pela geração do ritmo respiratório (FELDMAN \& MCCRIMMON, 2008; ABDALA et al., 2009). Portanto, a superfície ventral do bulbo e o NTS são regiões bulbares importantes para a geração e integração das funções cardiovasculares e respiratórias (Figura 1). 


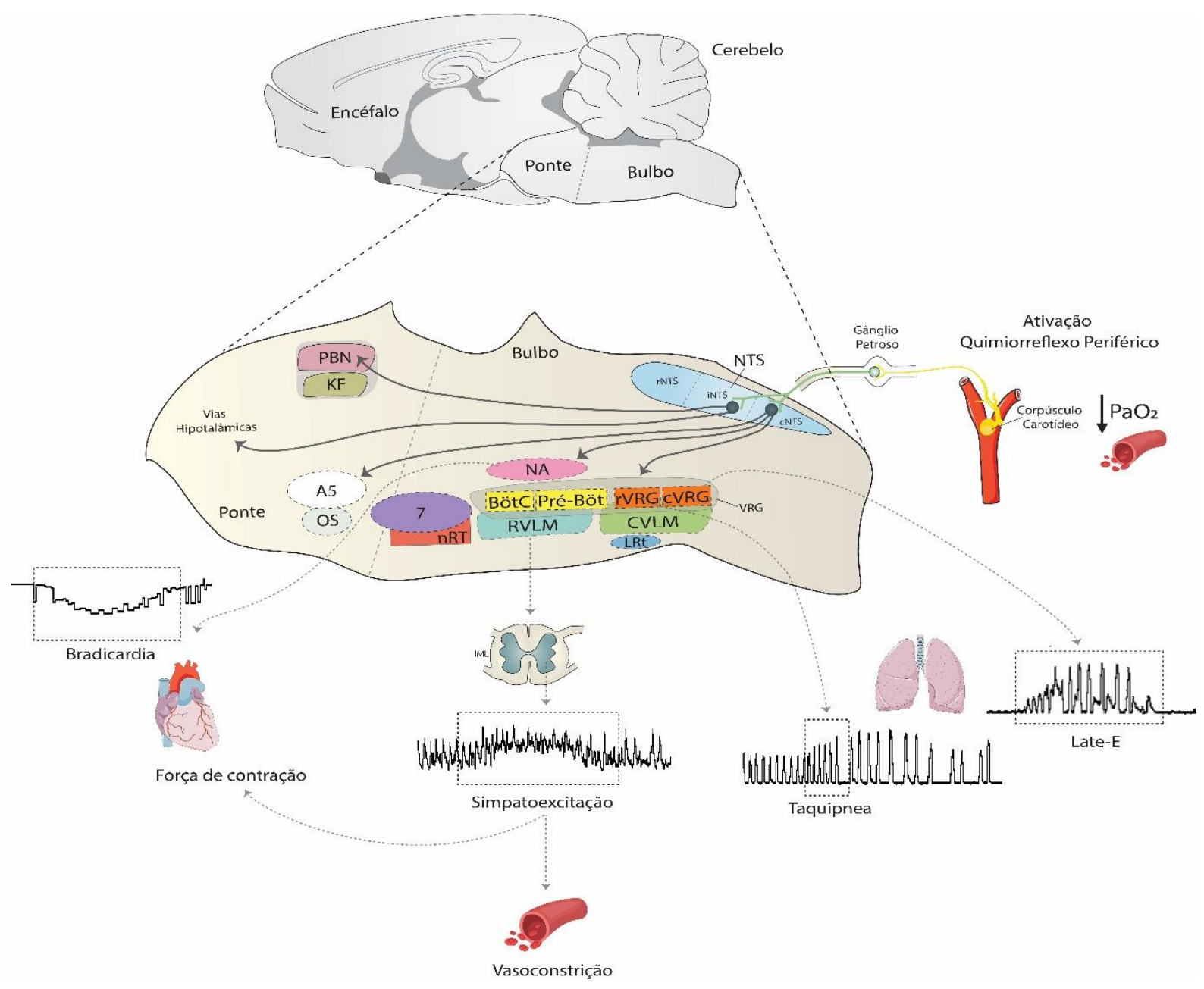

Figura 1: Representação esquemática dos núcleos pontinos e bulbares responsáveis pelo controle autonômico e respiratório e suas respostas à ativação do quimiorreflexo periférico. A diminuição na pressão parcial de oxigênio do sangue arterial $\left(\mathrm{PaO}_{2}\right)$ ativa os quimiorreceptores periféricos, localizados no corpúsculo carotídeo, levando a despolarização de neurônios aferentes que levam essa informação da periferia até o NTS. Os neurônios aferentes provenientes dos quimiorreceptores periféricos realizam sua primeira sinapse com neurônios de segunda ordem no NTS. Os neurônios de ordem superior do NTS enviam projeções para os neurônios pré-motores simpáticos do RVLM, neurônios pré-ganglionares parassimpático do NA e para neurônios do VRG. Em conjunto, essas regiões e núcleos do tronco encefálico promovem respostas cardiovasculares e respiratórias integradas as quais são caracterizadas por intensa bradicardia, simpatoexcitação (a qual promove vasoconstrição e aumento da força de contração do coração), taquipneia e um aumento da atividade dos músculos abdominais (expiração ativa ou Late-E). rNTS: núcleo do trato solitário rostral; iNTS: núcleo do trato solitário intermediário; CNTS: núcleo do trato solitário caudal; PBN: núcleo parabraquial; KF: núcleo do fuso de Kölliker; SO: oliva superior; 7: núcleo facial; nRT: núcleo retrotrapezóide; NA: núcleo ambíguo; RVLM: medula ventro-lateral rostral; CVLM: medula ventro-lateral caudal; BötC: complexo de Bötzinger; Pré-BötC: complexo pré-Bötzinger; rVRG: grupamento respiratório ventral rostral; cVRG: grupamento respiratório ventral caudal; VRC: coluna respiratória ventral; LRt: núcleo reticular lateral; IML: coluna intermédio lateral. 
O estímulo e a integração desses circuitos neuronais em uma situação de queda da $\mathrm{PaO}_{2}$, por meio da interação entre neurônios autonômicos e respiratórios, promove o acoplamento das respostas cardiovasculares e respiratórias necessárias para reestabelecer a homeostase frente a uma redução da $\mathrm{PaO}_{2}$. O aumento da ventilação tem por objetivo proporcionar uma maior eficiência do sistema respiratório na tentativa de promover um aumento captação de oxigênio $\left(\mathrm{O}_{2}\right)$ do ar atmosférico, enquanto que as respostas de elevação da pressão arterial e aumento da força de contração do coração tem como finalidade uma melhor redistribuição do fluxo sanguíneo, principalmente para as circulações coronária e cerebral. Além disso, a bradicardia observada neste reflexo ao reduzir a atividade metabólica do coração promove uma redução do consumo de oxigênio pelo coração. Em conjunto, estas respostas, que agem de forma rápida, garantem o aporte sanguíneo bem como a oferta de $\mathrm{O}_{2}$ adequado aos diferentes órgãos e tecido do indivíduo frente aos desafios fisiológicos (MACHADO, 2001; BARROS et al., 2002; COSTA et al., 2014).

O nosso laboratório tem se dedicado aos estudos sobre a neurotransmissão e a neuromodulação envolvidas no processamento dos componentes simpatoexcitatório e respiratório do quimiorreflexo no NTS e na superfície ventral do bulbo (incluindo o RVLM, BötC e pré-BötC). Dentre as diferentes abordagens experimentais utilizadas merecem destaques os modelos de ratos não-anestesiados e a preparação in situ coração-tronco encefálico isolados (WHBP). Estes estudos demostraram que existe uma modulação purinérgica e glutamatérgica das vias neurais do quimiorreflexo, mostrando que o glutamato e o ATP desempenham funções importantes nos diferentes grupamentos neuronais envolvidos nas respostas respiratórias e autonômicas do quimiorreflexo, tanto no NTS como nas diferentes sub-regiões do RVLM [(aspecto rostral - RVLM/BötC; aspecto caudal RVLM/pré-BötC; Figura 1) ANTUNES et al., 2005; BRAGA et al. (2007); MORAES et al. 2011, 2012].

Estudos do nosso laboratório também mostraram alterações na neurotransmissão dos componentes respiratório e simpático no NTS e na superfície ventral do bulbo em ratos submetidos à hipóxia crônica intermitente $(\mathrm{HCl})$, a qual se caracteriza como um modelo experimental da apnéia obstrutiva do sono (AOS), um distúrbio gerado pela obstrução das vias aéreas superiores, levando à ativação recorrente do quimiorreflexo (DEMPSEY et al., 2010). Trabalhos recentes do nosso 
laboratório demonstraram que ratos jovens submetidos a um protocolo experimental de $\mathrm{HCl}$ por 10 dias apresentam, quando comparados com animais controle, elevada atividade simpática basal, maior pressão arterial média e um padrão alterado de acoplamento da atividade simpática e respiratória, coerente com um perfil de expiração ativa (ZOCCAL et al., 2007a; 2008; 2009b; MORAES et al., 2013).

De forma semelhante à $\mathrm{HCl}$, estudos do nosso laboratório mostraram que ratos submetidos à hipóxia mantida $\left(\mathrm{HM} ; \mathrm{FiO}_{2}\right.$ 0,1 - 10\%) por 24 horas também apresentaram alterações cardiovasculares e respiratórias (ZOCCAL et al., 2008; MORAES et al., 2014 ACCORSI-MENDONÇA et al., 2015). Além disso, é importante destacar que indivíduos que se deslocam a elevadas altitudes são expostos a longos períodos de hipóxia mantida, induzindo alterações tanto nas funções autonômicas quanto respiratórias desses indivíduos, com concomitante aumento da pressão arterial e da ventilação pulmonar. Portanto, os ajustes nas atividades respiratórias e autonômicas ocorrem de forma simultânea e acoplada, com a finalidade de promover as alterações compensatórias necessárias frente ao desafio hipóxico (POWELL et al., 1998; CALBET, 2003; HANSEN \& SANDER, 2003; POWELL, 2007). Os estudos do nosso laboratório realizados em ratos corroboraram e estenderam estas observações ao documentarem importantes alterações no acoplamento simpático-respiratório após os protocolos de HM, as quais parecem contribuir para a hipertensão arterial observada neste modelo experimental (MORAES et al., 2014; ACCORSI-MENDONÇA et al., 2015).

Estudos de Moraes et al. (2014) mostraram que ratos jovens expostos à HM e estudados por meio da preparação in situ apresentaram padrão expiratório ativo, com aumento das atividades dos nervos abdominal, hipoglosso e vagal durante a expiração ativa (Late-E) e que estas alterações estão relacionadas a modificações da modulação da rede neural respiratória (BötC,e nRT). Além disso, foi observado na preparação in situ um aumento da atividade simpática torácica e dos níveis de pressão arterial nos animais acordados. Os autores sugeriram que estas alterações estariam associadas a um aumento da atividade neuronal dos neurônios présimpáticos do RVLM durante a fase Late-E e concluíram que a HM promove a ativação de neurônios expiratórios, o que poderia afetar o padrão de atividade motora expiratória e seu acoplamento com a atividade simpática (MORAES et al., 2014). 
Em relação às respostas autonômicas à ativação do quimiorreflexo na preparação in situ coração tronco encefálico isolados (preparação in situ), estudos anteriores mostraram que ratos jovens submetidos à HM apresentaram: a) uma resposta ventilatória mais prolongada (registro direto do nervo frênico), b) um aumento da magnitude das respostas parassimpato-excitatória (registro do eletrocardiograma) e c) uma resposta simpato-excitatória (registro direto do nervo simpático torácico) frente à ativação do quimiorreflexo com cianeto de potássio (KCN). Estes resultados indicaram uma facilitação do processamento sináptico das respostas cardiovasculares e respiratórias à ativação do quimiorreflexo após a HM (ACCORSI-MENDONÇA et al., 2015). Essas observações aumentaram o nosso interesse em estudar as alterações cardiovasculares decorrentes da exposição à hipóxia, bem como entender os mecanismos envolvidos nessas alterações.

Nos últimos anos o interesse do nosso laboratório em trabalhar com os camundongos aumentou devido principalmente as possibilidades que o uso dessa espécie proporciona em relação às diferentes modificações genéticas, as quais se tornaram indispensáveis para o melhor entendimento dos mecanismos envolvidos na neurotransmissão e neuromodulação da transmissão sináptica e da interação entre neurônios e astrócitos. Por outro lado, os resultados existentes na literatura em relação às alterações cardiovasculares e respiratórias de camundongos submetidos aos diferentes modelos de hipóxia experimental são muito variados, devido aos diferentes protocolos e desafios hipóxicos utilizados. Além disso, as dificuldades encontradas devido ao pequeno porte e ao difícil manuseio dessa espécie de roedores tanto in vivo como em preparações in situ tornam a análise, a comparação e principalmente a interpretação dos resultados bastante diversificados (PATON, 1996a; PATON, 1996b; PATON \& BUTCHER, 1998; CAMPEN et al., 2004, 2005; SCHWENKE et al., 2006; ISHIGURO et al., 2006; PENG et al., 2006; LIN et al., 2007; PEARSON et al., 2007; BRAGA et al., 2008; DEMATTEIS et al., 2008; CHU et al., 2015; ZHANG et al., 2015; PAN et al., 2016; LEE \& LIAO, 2018; ALLWOOD et al., 2018; TAKAHASHI et al., 2018; BARRETT et al., 2019). Neste contexto, estudos anteriores mostraram diferentes magnitudes nas respostas cardiovasculares (elevação da pressão arterial e bradicardia) em camundongos submetidos à HM (CAMPEN et al., 2004, 2005; SCHWENKE et al., 2006; ISHIGURO et al., 2006; 
PEARSON et al., 2007; ZHANG et al., 2015; PAN et al., 2016; BARRETT et al., 2018).

Em relação ao padrão neural da atividade respiratória em camundongos, ele já foi descrito em estudos anteriores usando a preparação in situ coração-tronco encefálico (WHBP) (PATON \& RICHTER, 1995; PATON, 1996a; 1996b; PATON \& BUTCHER, 1998; STETTENER et al., 2007; 2008; 2011). Nesta condição experimental, os camundongos apresentam padrão respiratório eupneico e os reflexos cardiovasculares e respiratórios estão preservados. Em estudos anteriores, camundongos apresentaram um ciclo respiratório de quatro fases [pré-inspiratório (Pré-I), inspiratório (Insp), pós-inspiratório (Pós-I) e expiração final (E2) (PATON \& RICHTER, 1995; PATON, 1996a; 1996b; PATON \& BUTCHER, 1998; STETTENER et al., 2007; 2008; 2011). Diferentes grupamentos neuronais excitatórios e inibitórios que se autorregulam constituem uma rede neuronal respiratória, a qual participa de cada uma dessas fases do ciclo respiratório, incluindo a geração e a modulação do padrão respiratório (Figura 1). Além disso, estes estudos mostraram que há uma alteração dependente da idade no padrão motor respiratório destes animais. Estes dados in vivo e in vitro indicam que esta rede respiratória neural dos camundongos parece estar madura e estável a partir do $15^{\circ}$ dia do período pós-natal e que o padrão respiratório é uma característica fenotípica herdada geneticamente. (TANKERSLEY et al, 1997; PATON \& RICHTER, 1995; PATON, 1996a; PATON, 1996b; PATON \& BUTCHER, 1998; TANKERSLEY, 1999; TANKERSLEY, 2000; HAN \& STROHL, 2000; LEE \& LIAO, 2018).

Como descrito anteriormente, os ratos jovens quando submetidos ao protocolo de HM apresentam alterações autonômicas e respiratórias que favorecem o desenvolvimento de hipertensão nestes animais (MORAES et al., 2014; ACCORSIMENDONÇA et al., 2015). No entanto, as atividades dos nervos frênico, abdominal, simpático e vago que são responsáveis pelo acoplamento simpático-respiratório e, consequentemente, pelas possíveis alterações cardiovasculares e respiratórias em camundongos submetidos à $\mathrm{HM}$ ainda não haviam sido avaliadas. Portanto, considerando: a) a grande diversidade de respostas, b) a relevância dos camundongos como modelo experimental para o estudo dos mecanismos neurais envolvidos nas alterações autonômicas e respiratórias em resposta à $\mathrm{HM} \mathrm{e} \mathrm{c)} \mathrm{que} \mathrm{as}$ respostas autonômicas e respiratórias do quimiorreflexo estão alteradas após à HM 
em ratos, no presente estudo investigamos as alterações cardiovasculares e respiratórias de camundongos C57BL/6 submetidos ao protocolo de $\mathrm{HM}$ previamente utilizado no nosso laboratório para ratos (MORAES et al., 2014; ACCORSI-MENDONÇA et al., 2015). 
Hipótese do trabalho 


\section{HIPÓTESE DO TRABALHO}

Camundongos submetidos ao protocolo de HM apresentam alterações cardiovasculares, autonômicas e respiratórias semelhantes àquelas observadas em ratos jovens submetidos ao mesmo protocolo de HM. 
Objetivos 


\section{OBJETIVOS}

\subsection{Objetivos Gerais:}

$\checkmark$ Avaliar se camundongos submetidos à $\mathrm{HM}$ apresentam alterações cardiovasculares similares àquelas observadas no rato;

$\checkmark$ Caracterizar o padrão das atividades de nervos autonômicos e respiratórios basais utilizando a preparação in situ de camundongos controle ou HM;

$\checkmark$ Caracterizar o padrão das atividades de nervos autonômicos e respiratórios à ativação do quimiorreflexo periférico e central utilizando a preparação in situ de camundongos controle ou HM.

\subsection{Objetivos específicos}

$\checkmark$ Avaliar a frequência cardíaca (FC) basal de camundongos na preparação in situ previamente submetidos à $\mathrm{HM}$ e dos seus respectivos controles;

$\checkmark$ Avaliar a atividade basal dos nervos respiratórios (frênico, abdominal e vago cervical) de camundongos na preparação in situ previamente submetidos à $\mathrm{HM}$ e dos seus respectivos controles;

$\checkmark$ Avaliar a atividade basal dos nervos autonômicos (simpático torácico e vago cervical) de camundongos na preparação in situ previamente submetidos à $\mathrm{HM}$ e dos seus respectivos controles;

$\checkmark$ Avaliar as alterações na frequência cardíaca (FC) de camundongos em resposta à ativação do quimiorreflexo periférico em camundongos na preparação in situ previamente submetidos à $\mathrm{HM}$ e dos seus respectivos controles;

$\checkmark$ Avaliar as alterações nas atividades dos nervos respiratórios (frênico, abdominal e vago cervical) de camundongos em resposta à ativação do quimiorreflexo periférico em camundongos na preparação in situ submetidos previamente submetidos à $\mathrm{HM}$ e dos seus respectivos controles;

$\checkmark$ Avaliar as alterações nas atividades dos nervos autonômicos (simpático torácico e vago cervical) de camundongos em resposta à ativação do quimiorreflexo periférico em camundongos na preparação in situ previamente submetidos à $\mathrm{HM}$ e dos seus respectivos controles; 
Materiais e métodos 


\section{MATERIAS E MÉTODOS}

\subsection{Animais:}

Em todos os protocolos experimentais foram utilizados 34 camundongos machos adultos da linhagem C57BL/6 (6 - 8 semanas com peso aproximado de 22g) fornecidos pelo Biotério Central do Campus da USP de Ribeirão Preto e mantidos em caixas coletivas (no máximo 4 animais por caixa) no Biotério de Manutenção e Experimentação de camundongos da FMRP localizado no Departamento de Farmacologia da FMRP-USP. Os animais foram mantidos em ambiente com temperatura média de $22^{\circ} \mathrm{C}$, ciclo de claro-escuro artificial de 12 horas e alimentados com ração granulada e água ad libitum. O presente projeto foi aprovado pela Comissão de Ética no Uso de Animais na Experimentação (CEUA) da FMRP-USP e registrado com o número 163/2019.

\subsection{Hipóxia Mantida (HM) e Normóxia (Controle):}

Os camundongos dos grupos controle (normóxia) e hipóxia mantida (HM) foram acondicionados individualmente em caixas de acrílico (caixa $A-30 \times 20 \times 13 \mathrm{~cm}$ ) cedidas pelo Biotério de Manutenção e Experimentação de camundongos da FMRP com ração e água ad libitum e mantidos em câmaras de acrílico (volume de $210 \mathrm{~L}$ ) equipadas com injetores de gases e sensores de $\mathrm{O}_{2}, \mathrm{CO}_{2}$, temperatura e umidade. Os animais do grupo HM foram expostos à hipóxia mantida, a qual consiste de injeção frequente do gás nitrogênio ( $\mathrm{N}_{2}$ - Maxiair, Ribeirão Preto, Brasil) ao longo de $24 \mathrm{~h}$ com o objetivo de reduzir a fração inspirada de $\mathrm{O}_{2}\left(\mathrm{FiO}_{2}\right)$ de 0,208 para 0,10, permanecendo neste nível por todo o período. A injeção do gás $\mathrm{N}_{2}$ dentro das câmaras foi regulada por um conjunto de válvulas solenóides [Oxycycler (Modelo A84XOV) Biospherix, EUA], as quais são automaticamente operadas por um software (AnaWin 2, versão 2.4.17). Os camundongos dos grupos controle foram mantidos em câmaras similares, porém em condições de normóxia ao longo de 24 horas. 


\subsection{Experimentos com a preparação in situ coração tronco encefálico isolados de camundongos:}

\subsubsection{Solução de Perfusão [fluido cerebroespinhal artificial modificado (aCFS)]:}

A solução artificial utilizada na perfusão da preparação in situ substitui o sangue e é utilizada para manter a preparação in situ viável durante todo o experimento. A solução é composta por (mM): 125 de $\mathrm{NaCl} ; 24$ de $\mathrm{NaHCO}_{3} ; 5$ de $\mathrm{KCl} ; 2,5$ de $\mathrm{CaCl}_{2} ; 1,25$ de $\mathrm{MgSO}_{4} ; 1,25$ de $\mathrm{KH}_{2} \mathrm{PO}_{4}$ e 10 de dextrose diluídos em água deionizada. Outras substâncias foram adicionadas à solução de perfusão como um agente oncótico (Ficoll 70, 1.25\%, Sigma, St. Louis, MO, EUA) e uma droga bloqueadora da transmissão neuromuscular (vecurônio, 3-4 $\mu \mathrm{g} \mathrm{ml}^{-1}$, Cristália, Itapira, SP, Brazil), com a finalidade de inibir os movimentos da musculatura da caixa torácica. Durante todo o período de perfusão, a solução foi aerada com uma mistura carbogênica ( $95 \%$ de $\mathrm{O}_{2}$ e $5 \%$ de $\mathrm{CO}_{2}$, Maxiair, Ribeirão Preto, Brasil) para fornecer $\mathrm{O}_{2}$ à preparação in situ e para manter o pH em valores próximos a 7,4.

\subsubsection{Procedimento Cirúrgico:}

Em grupos distintos de camundongos $\mathrm{HM}$ e controle, registramos os nervos autonômicos e respiratórios usando a preparação in situ coração-tronco encefálico, a qual foi originalmente descrita por Paton (1996a) e utilizada nos estudos de Stettner et al. $(2007,2008,2011)$. Ao final dos protocolos de HM e normóxia, os camundongos foram profundamente anestesiados com isoflurano (Isoforine $\AA$, Cristália Produtos Químicos Farmacêuticos Ltda., Itapira, SP, Brazil) e seccionado sub-diafragmaticamente. A cabeça e o tórax foram imersos em uma solução de ACSF (Solução de Ringer) acondicionada em uma cuba em contato com gelo, para mantê-la resfriada $\left(8-4^{\circ} \mathrm{C}\right)$, e sob aeração constante com carbogênio $\left(95 \% \mathrm{O}_{2} \mathrm{e}\right.$ $5 \%$ de $\mathrm{CO}_{2}$ ). Em seguida, o animal foi descerebrado ao nível pré-colicular e a pele foi completamente removida para evitar que os pelos contaminassem a solução de perfusão e obstruíssem o sistema de perfusão. A descerebração torna os animais insensíveis ao processamento sensorial da dor e a partir dessa etapa a preparação fica livre dos efeitos do anestésico. Logo após, foi realizada a remoção das vísceras, do diafragma, dos pulmões e dos ventrículos cardíacos, enquanto os átrios 
permaneceram intactos e o nervo frênico (NF) foi isolado e seccionado junto à base do diafragma.

A preparação in situ foi então transferida para uma câmara de registros e a aorta descendente foi canulada e perfundida retrogradamente com ACSF, usandose uma bomba peristáltica [(modelo 502S) Watson-Marlow 505S, Falmouth, UK] com pressão e fluxo constantes $\left(50-70 \mathrm{mmHg} / 11-18 \mathrm{~mL} \mathrm{~min}^{-1}\right)$. Com a finalidade de auxiliar na manutenção da pressão de perfusão e adequada perfusão do tronco encefálico e do coração foi adicionada vasopressina [0,6-1,2 nM, (Sigma-Aldrich, St. Louis, MO, USA) a solução de perfusão. A bomba de perfusão foi controlada pelo computador usando um script (Spike 2; Versão 7; Cambridge Electronic Design, UK). O perfusato foi constantemente aerado com carbogênio e aquecido por meio de um trocador de calor e mantido a uma temperatura de aproximadamente $31^{\circ} \mathrm{C}$. Esse perfusato foi filtrado utilizando-se um pré-filtro de polipropileno de $25 \mathrm{~mm}$ de diâmetro e $25 \mu \mathrm{m}$ de tamanho do poro (Millipore, Billirica, MA, USA). A filtração evita a passagem de coágulos sanguíneos e restos de tecidos em suspensão para 0 interior da preparação in situ. Finalmente, o perfusato passou através de uma "armadilha para bolhas", a qual possui duas funções: (1) evitar a passagem de bolhas de ar para a preparação e (2) amortecer as pulsações geradas pela bomba peristáltica. Todos os tubos utilizados no sistema de perfusão são relativamente impermeáveis ao $\mathrm{O}_{2}$ e ao $\mathrm{CO}_{2}$ [ID: 1,56 mm; OD: 4,7 mm (Tygon Cole Palmer, EUA)]. A porção final do tubo é uma cânula de duplo lúmem [ID: 0,28mm; OD: 0,61 mm (Portex, EUA)], sendo um para a perfusão e outro para o registro da pressão de perfusão (PP). Essa cânula foi conectada a um transdutor de pressão e o sinal foi então transmitido para um amplificador e deste para o computador, no qual se encontra instalado o software Spike 2 (Cambrigde Electronic Design, UK), por meio do qual foi realizada as aquisições e as análises dos sinais obtidos (Figura 2).

4.3.3. Registros da frequência cardíaca e das atividades dos nervos frênico, simpático torácico, vago cervical e abdominal na preparação in situ coração tronco encefálico isolados:

Após a secção do nervo frênico ao nível do diafragma, os seus potenciais foram registrados por meio de um eletrodo de vidro de sucção (micropipeta de vidro com diâmetro: 0,2 - 0,3 mm) acoplado a um micromanipulador (UMM-3C, Narishige, 
Setagaya, Japan), o qual foi conectado a um pré-amplificador. Do amplificador parte também uma via para o computador, o qual utiliza o software Spike 2 para a digitalização dos registros.

Após a dissecação do ramo simpático paravertebral entre os níveis da T8-T12, o nervo eferente simpático torácico também foi seccionado e seus potenciais registrados utilizando outro eletrodo de vidro, seguindo os mesmos procedimentos para o registro da atividade do nervo frênico. Por meio deste registro, foi possível obter a frequência de despolarização do nervo eferente simpático torácico (tANS). Procedimento semelhante foi utilizado para o registro da atividade do nervo vago (cNV) cervical direito. O nervo abdominal (AbN) foi isolado a partir dos músculos abdominais oblíquos ao nível toracolombar e seccionado distalmente (Figura 2). Eletrodos bipolares foram colocados próximo aos átrios e usados para registro da frequência cardíaca (FC). Todos os sinais foram amplificados (Differential AC Amplifier model 1700, A-M Systems, Sequim, WA, USA), filtrados por "bandpass" (0.3-5 kHz), digitalizados [CED Micro1401; Cambridge Electronic Design (CED); Cambridge, UK] e registrados em unidades absolutas $(\mu \mathrm{V})$ em um computador (sampling rate: $5 \mathrm{kHz}$ ) utilizando o software Spike 2 (version 7, CED, Figura 2).

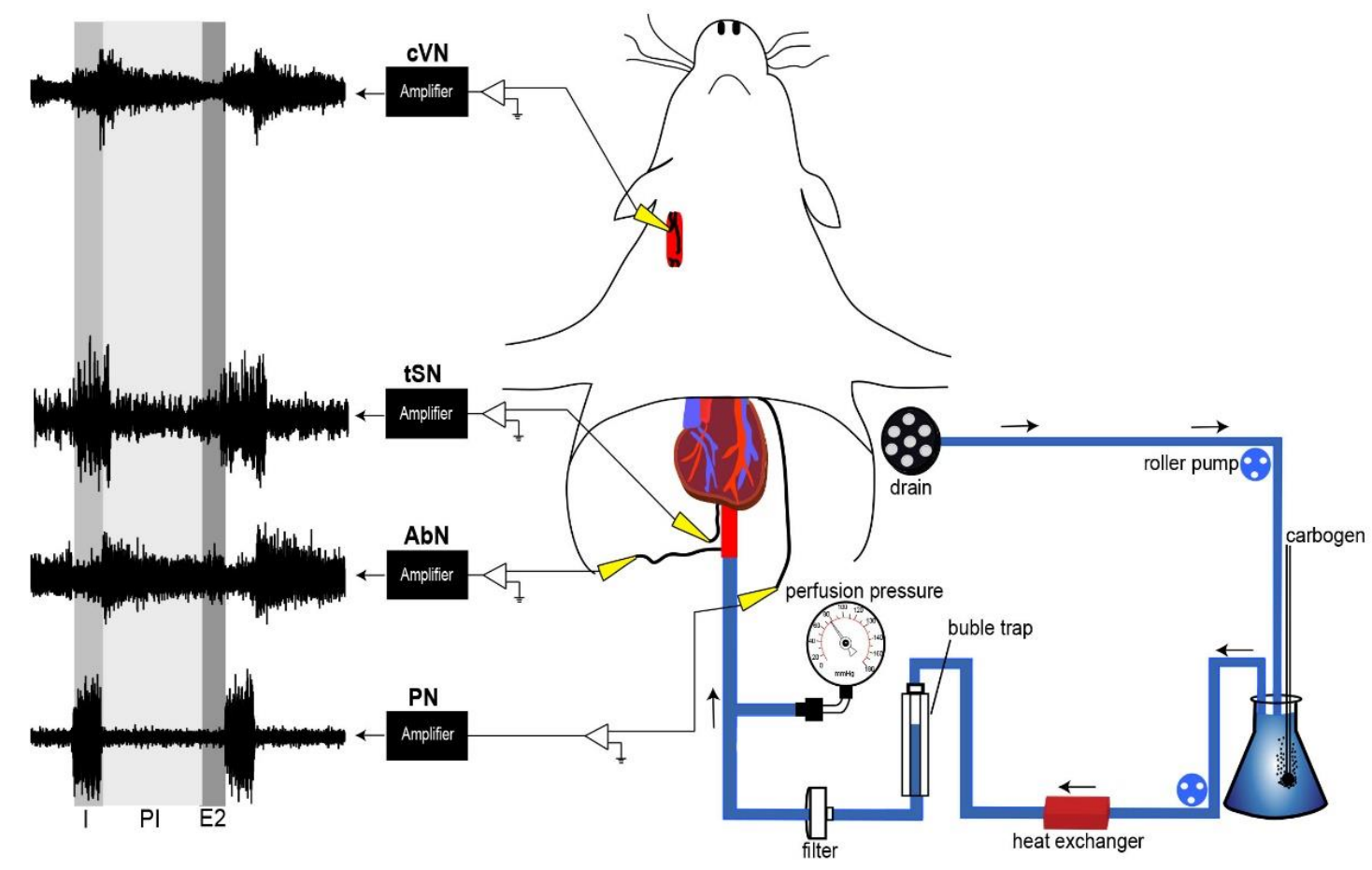

Figura 2: Representação esquemática da preparação in situ coração-tronco encefálico isolados (Modificado de Moraes et al, 2015), mostrando os registros dos nervos vago cervical (cVN), simpático torácico (tSN), abdominal (AbN) e frênico (PN). 
4.3.4. Ativação do quimiorreflexo periférico na preparação in situ coração tronco encefálico isolados:

A ativação dos quimiorreceptores periféricos foi feita como descrito por Franchini \& Krieger (1993), por meio da administração de cianeto de potássio [KCN, $(20 \mu \mathrm{g} / 50 \mu \mathrm{L})$ Sigma-Aldrich, St. Louis, MO, USA] na aorta descendente utilizando uma seringa acoplada ao sistema de perfusão como descrito em estudos anteriores realizados em camundongos (Paton \& Butcher, 1998) e ratos (Paton et al., 1999, 2002; Antunes et al., 2005; Braga et al., 2006, 2007).

\subsection{Protocolos experimentais na preparação in situ}

Registramos simultaneamente as atividades neurais basais de FC, NF, cVN, tSN e AbN. Todos os sinais dos nervos autonômicos e respiratórios apresentaram estabilidade confiável somente após 2 horas de registros basais e sob um controle refinado da pressão de perfusão. Assim, para a análise dos resultados, não foram considerados os registros realizados ao longo das 2 horas iniciais. Após essa estabilização completa, os primeiros 10 minutos foram considerados para análise dos parâmetros basais e o quimiorreflexo periférico foi ativado duas vezes sucessivas com um intervalo de 15 minutos. Após os protocolos experimentais realizados na preparação in situ, as preparações foram, ao final, sacrificadas por meio do desligamento da bomba de perfusão (Figura 3).

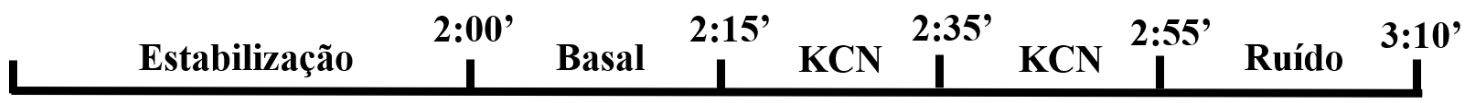

Figura 3: Esquema representativo do protocolo experimental utilizado para estímulo do quimiorreflexo periférico. 


\subsection{Análise dos resultados obtidos por meio dos registros neurais na preparação in situ}

Nas preparações in situ de camundongos controle e HM, nervos autônomicos e respiratórios foram analisados em sinais retificados e suavizados (constante de tempo: $50 \mathrm{~ms}$ ) usando o software Spike 2 (versão 7, CED). Obtivemos os níveis de ruídos elétricos nos registros dos nervos tSN e AbN calculando os valores médios dos sinais neurais nos 15 minutos finais após a morte da preparação. Analisamos a frequência média dos disparos do NF em um período de 60 segundos, a qual foi expressa em Hertz $(\mathrm{Hz})$. Os registros dos NF e cVN foram utilizados para determinar a duração das quatro fases do ciclo respiratório, de acordo com a ilustração apresentada na Figura 4: a) Pré-inspiração (Pré-I), correspondente ao período entre o início do aumento da atividade do cVN e o início do disparo do NF; b) Inspiração (Insp), coincidente com o disparo do PN; c) Pós-inspiração (Pós-I), correspondendo ao período entre o início da expiração e o final da atividade decrescente do cVN; e d) expiração final (E2), começando no encerramento da atividade do cVN e terminando no início do disparo do NF (Patton, 1996b; Stettener et al., 2007; 2008; 2011; Smith et al., 2007; Moraes et al, 2012; 2013). As durações de cada fase do ciclo respiratório foram calculadas pela média a partir de 10 ciclos respiratórios e expressas em segundos (s). A partir dos mesmos 10 ciclos, as atividades médias de tSN e cVN foram calculadas durante as fases Insp, Pós-I e E2, como descrito em estudos anteriores (Stettner et al, 2007; 2008; 2011; Smith et al., 2007; Moraes et al, 2012; 2013; Richter \& Smith, 2014). Para isso, determinamos uma escala de atividade de $0-100 \%$, na qual $100 \%$ corresponde ao pico das atividades tSN e cVN observadas durante a inspiração/pós-inspiração e 0\% ao nível de ruído obtido após a morte da preparação in situ. 


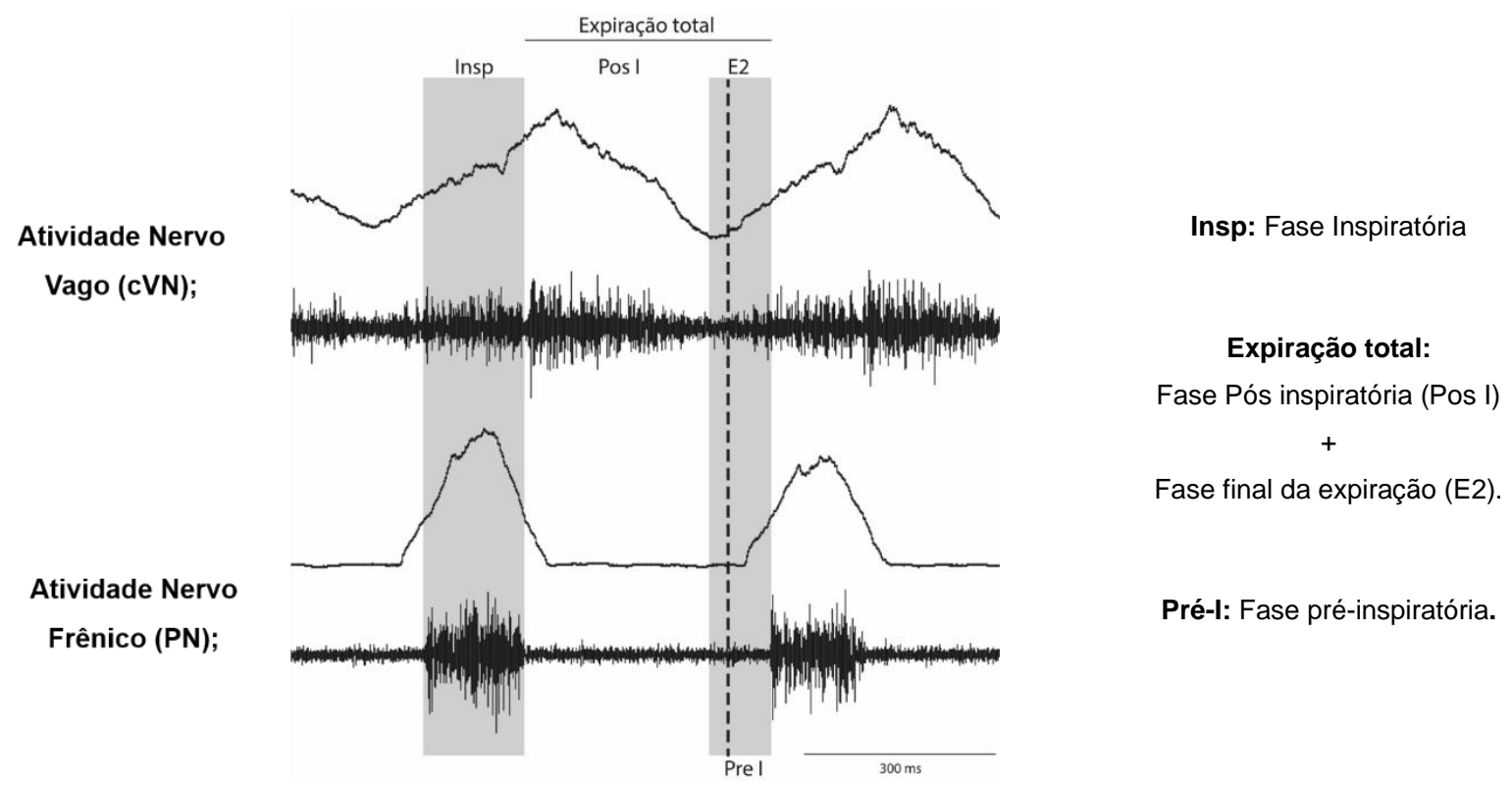

Figura 4: Esquema representativo da divisão das fases do ciclo respiratório de camundongos submetidos a preparação in situ coração tronco encefálico isolados. Camundongos apresentaram um ciclo respiratório de quatro fases: Pré-inspiratória (pré-I), Inspiratório (Insp), pósinspiratória (Pós-I) e expiração final (E2). Em conjunto, as fases Pós-I e E2 compõem a expiração total, as quais são determinadas pela correlação da atividade do nervo vago cervical (cVN) e atividade do nervo frênico (PN).

O aumento da amplitude da atividade AbN durante a fase E2 acima dos níveis tônicos pós inspiratórios foram definidos como eventos expiratórios ativos [(Late-E) Figura 5]. A incidência de eventos $A b N$ late-E foi calculada como uma porcentagem em relação ao número total de ciclos respiratórios registrados em 60 segundos. Mudanças na atividade da $\mathrm{FC}$ e $\mathrm{tSN}$ em resposta à ativação do quimiorreflexo foram calculadas a partir de duas ativações sucessivas com KCN. A magnitude da resposta bradicardica foi calculada como sendo a variação entre os picos das respostas e os valores basais imediatamente anteriores à estimulação do quimiorreflexo. A mudança na atividade $\mathrm{tSN}$ foi calculada durante a ativação do quimiorreflexo como um aumento percentual na atividade neural média em relação aos valores basais imediatamente anteriores à estimulação do quimiorreflexo. 


\subsection{Análise estatística}

Os resultados são expressos como média \pm desvio padrão (DP). As distribuições dos dados foram testadas usando o teste de normalidade Shapiro-Wilk. $\mathrm{Na}$ comparação das médias de variâncias iguais, realizamos os testes $\mathrm{t}$ de Student não pareado. Quando as variâncias foram significativamente diferentes (teste F; P $\leq$ $0,05)$, realizamos os testes $t$ de Student não pareados com a correção de Welch. Também usamos ANOVA-One-way e ANOVA-Two-way seguida de pós-teste de Bonferroni. Teste t de Student e ANOVA-One-way foram utilizadas para comparar as diferenças dos parâmetros de um mesmo grupo e ANOVA-Two-way para comparações das diferenças entre os grupos controle e HM. As diferenças foram consideradas estatisticamente significativas quando $P \leq 0,05$. Todos os gráficos $e$ análises estatísticas foram realizados usando GraphPad Prism 8 (GraphPad Software, La Jolla, CA, EUA). 
Resultados 


\section{RESULTADOS}

\subsection{Parâmetros respiratórios, cardiovasculares e autonômicos basais na preparação in situ de camundongos controle e HM.}

Na figura 5 temos a ilustração dos traçados representativos dos registros da frequência cardíaca (FC) basal, das atividades respiratória e autonômicas na preparação in situ de um camundongo do grupo controle e de outro camundongo submetido ao protocolo de HM. A FC basal dos animais dos grupos controle $(n=12)$ e HM $(n=10)$ não foram estatisticamente diferentes (369 \pm 55 vs $411 \pm 63$ bpm, $\mathrm{P}=0,1364$; Figura 5, painéis $\mathrm{A}$ e $\mathrm{B}$ e Figura 6, painel A). O padrão dos disparos do nervo frênico (DNF) foi similar nos 2 grupos experimentais (Figura 5, painéis $A$ e $B$ ). O padrão da atividade do nervo vago cervical (cVN) apresentou um componente inspiratório (aumento da atividade vagal simultaneamente ao DNF) e um componente pós inspiratório (Pós-l; Figura 5, painel A). Por outro lado, os camundongos HM apresentaram um padrão similar de atividade do cVN, porém a duração da fase Pós-I foi significativamente mais longa do que aquela observada no grupo controle (Figura 5, painel B e Figura 6, painel E). A atividade do nervo simpático torácico (tSN) apresentou o seu pico durante a fase Pós-I nos 2 grupos experimentais (Figura 5, painéis $A$ e $B$ ). Em relação à atividade do nervo abdominal $(\mathrm{AbN})$ nos camundongos controle ocorreram pequenas variações durante o ciclo respiratório, enquanto que nos camundongos $\mathrm{HM}$ ocorreram muitas expirações ativas, as quais são caracterizadas pelo aumento da amplitude da atividade do AbN durante a fase E2 do ciclo respiratório (eventos Late-E), como indicados pelas setas pretas na Figura 5, painel B. 


\subsection{Parâmetros respiratórios na preparação in situ de camundongos controle e HM.}

A frequência de disparos do nervo frênico (DNF) foi significativamente menor nos camundongos submetidos à $H M[n=11 ;(0,69 \pm 0,18$ vs $1,10 \pm 0,46 \mathrm{~Hz}$, $P=0,0017)]$ quando comparada com os camundongos do grupo controle $[n=23$, (Figura 5, painéis A e B e Figura 6, painel B)]. A incidência de eventos Late-E (expirações ativas) na atividade $A b N$ no grupo $\mathrm{HM}(\mathrm{n}=10)$ foi significativamente maior em relação ao grupo controle [( $n=20), 83,3 \pm 24,4$ vs $24,3 \pm 36,1 \%, P<0,0001$, (Figura 5, painéis A e B; Figura 6, painel C)].

Nas análises relativas ao tempo de duração das fases do ciclo respiratório, foi observado que o tempo de expiração (Exp) foi mais longo que o tempo de inspiração (Insp) nos grupos controle $[n=22,(0,67 \pm 0,32$ vs $0,25 \pm 0,08 s, P<0,0001$, Figura 5, painel A e Figura 6, painel D)] e HM $[n=11,(1,13 \pm 0,55$ vs $0,30 \pm 0,16 s, P<0,0001$; Figura 5, painel $B$ e Figura 6 , painel $D$ ). Além disso, verificamos que a fase Pós-l foi significativamente mais longa nos camundongos $\operatorname{HM}[n=11,(0,78 \pm 0,41$ vs $0,35 \pm$ 0,19 s, $P<0,0001$, Figura 5 , painel $B$ e Figura 6 , painel E)] quando comparada a mesma fase dos camundongos controle $(n=22)$. Quando analisamos as outras fases do ciclo respiratório de forma mais detalhada, observamos que a duração da fase E2 não foi diferente entre os animais dos grupos controle e $\mathrm{HM}(0,34 \pm 0.16$ vs $0,29 \pm$ $0,18 \mathrm{~s}, \quad P>0,9999$, Figura 6 , painel E). A fase pré-inspiratória (Pré-I) foi significativamente mais longa nos camundongos submetidos à $\mathrm{HM}(0,26 \pm 0,12$ vs $0,08 \pm 0,02 \mathrm{~s}, P=0.0432$, Figura 6 , painel $E$ ) quando comparada com a mesma fase dos camundongos controle. O tempo da expiração total nos camundongos $\mathrm{HM}$ $(\mathrm{n}=11)$ foi significativamente maior em relação aos camundongos do grupo controle [ $n=22,(1,13 \pm 0,55$ vs $0,67 \pm 0,32 s, P=0,0010$, Figura 5 , painel $B$ e Figura 6 , painel D)]. Esse tempo aumentado do período correspondente à expiração está associado ao aumento observado tanto na duração da fase Pós-l $(0,78 \pm 0,41$ vs $0,35 \pm 0,19$ s, $P<0,0001$, Figura 6, painel E) quanto na duração da fase Pré-I $(0,26 \pm 0,12$ vs $0,08 \pm$ $0,02 s, P=0,0432$, Figura 6, painel $E$ ). 

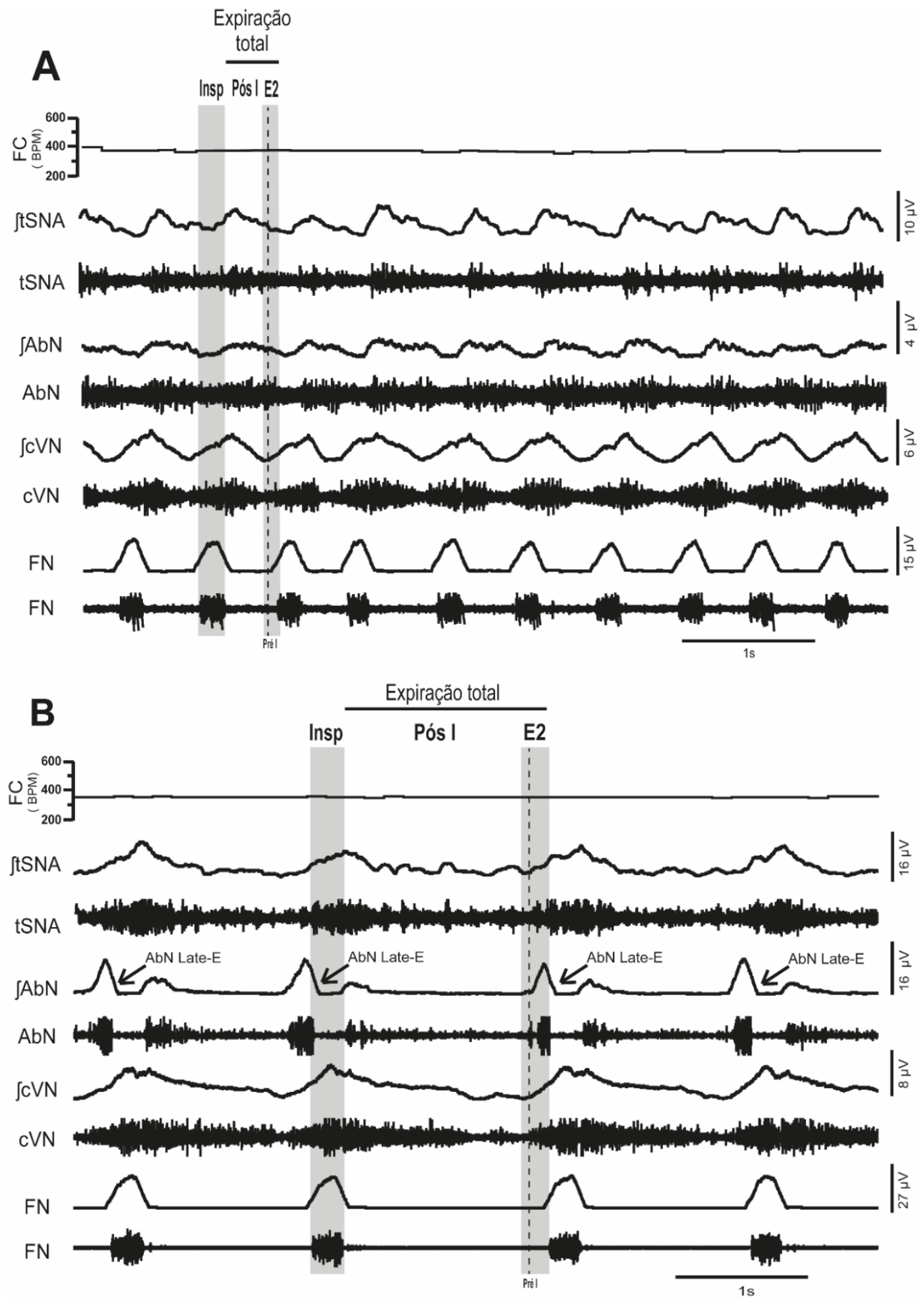

Figura 5: Traçados representativos dos registros da frequência cardíaca e dos registros dos nervos autonômicos e respiratórios basais na preparação in situ de camundongos controle e HM. Traçados representativos de preparações in situ de um camundongo controle (painel A) e um camundongo HM (painel B) mostrando a frequência cardíaca basal (FC), e atividades bruta e integrada $(\delta)$ dos nervos simpático torácico ( $\mathrm{SSN})$, nervo abdominal $(\mathrm{AbN})$ nervo vago cervical $(\mathrm{cVN})$ e nervo frênico (NF). A linha tracejada marca o início da fase Pré-I, a qual termina no começo da atividade em burst do NF. Insp: inspiratório, Pós-I: primeiro estágio da expiração, E2: segundo estágio da expiração. As setas indicam os eventos Late-E na atividade AbN. 

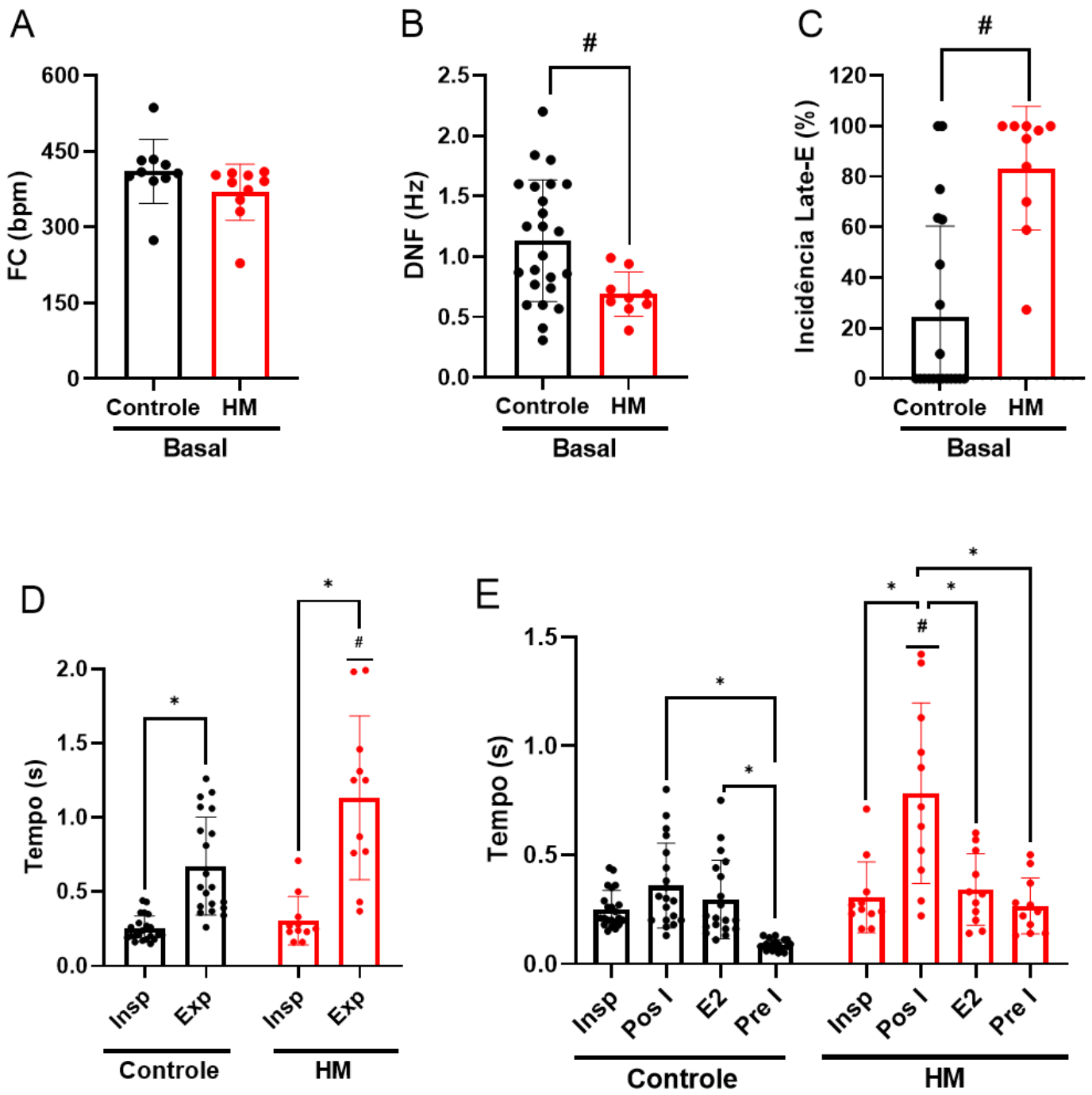

Figura 6: Valores médios da frequência cardíaca e dos parâmetros respiratórios na preparação in situ de camundongos controle e HM. Frequência cardíaca basal (FC, painel $A$ ) do grupo controle $(n=12)$ e HM $(n=10)$. Frequência da atividade de disparo do nervo frênico (DNF, painel B) de camundongos do grupo controle $(n=23)$ e HM $(n=11)$. Incidência de eventos Late- $E$ na atividade do nervo abdominal (painel C) de camundongos controle $(n=20)$ e HM $(n=11)$. Duração das fases do ciclo respiratório (painéis $D$ e E) de camundongos controle $(n=22)$ e HM $(n=11)$. Insp: Inspiração, Exp: expiração total, Pós-I: primeiro estágio da expiração, E2: segundo estágio da expiração e Pré-I: préinspiração. * Diferente entre fases do mesmo grupo. \# diferente em relação ao grupo controle $(p<0,05)$. Teste t não pareado (painel $A-C$ ) e ANOVA de uma via para comparar fases no mesmo grupo e ANOVA de duas vias para comparar as diferenças entre os grupos (painéis $D$ e E). 


\subsection{Atividades basais dos nervos vago cervical e simpático torácico na preparação in situ de camundongos controle e HM.}

Atividade basal do cVN durante a fase Pós-I foi significativamente maior em camundongos $\mathrm{HM}(\mathrm{n}=11)$ quando comparada aos camundongos controle $[\mathrm{n}=21$, $(53,4 \pm 10,3$ vs $33,1 \pm 7,0 \%, P<0,0001$, Figura 5 , painel B e Figura 7 , painel A). A atividade basal do cVN durante a inspiração $(26,4 \pm 4,4$ vs $32,5 \pm 8,4 \%, P=0,0904$, Figura 7, painel A) e a fase E2 $(21, .0 \pm 3,9$ vs $25,1 \pm 6,9 \%, P=0,4596$, Figura 7 , painel A) não foram diferentes entre os grupos. Por outro lado, a atividade simpática basal nos camundongos do grupo HM $(n=10)$ foi significativamente menor na fase E2 em comparação com os camundongos do grupo controle [ $\mathrm{n}=16$, $(19,0 \pm 12,9$ vs $39,7 \pm 16,8 \%, P=0,0041$, Figura 7 , painel $B)]$. As atividades do tSN durante a inspiração $(28,6 \pm 11,4$ vs $40,8 \pm 14,5 \%, P=0,1870$, Figura 7 , painel B) e na fase Pós-I ( $37,9 \pm 14,5$ vs $51,7 \pm 15,6 \%, P=0,1072$, Figura 7 , painel $B)$ não foram diferentes entre os grupos controle e HM.
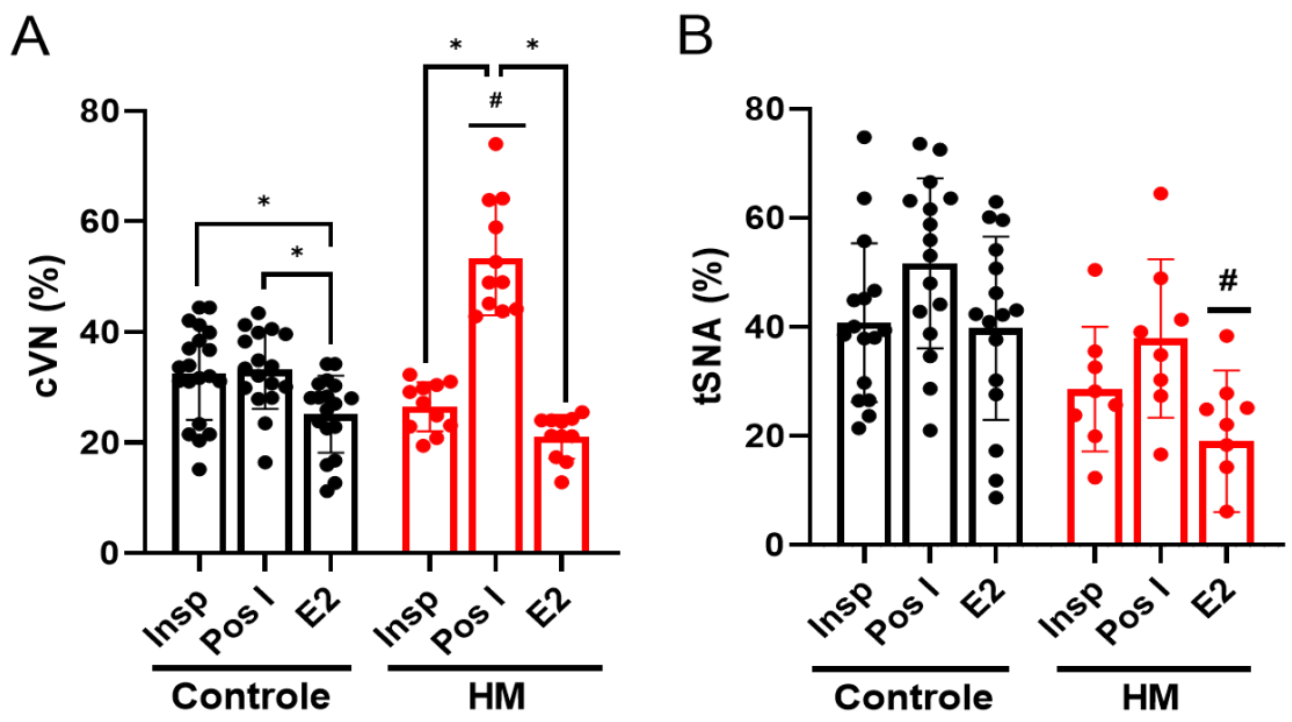

Figura 7: Valores médios da atividade dos nervos vago cervical e simpático torácico durante as fases do ciclo respiratório na preparação in situ de camundongos do grupo controle e HM. Atividade basal do nervo vago cervical $[(\% \mathrm{cVN}$, painel $A$, camundongos do grupo controle $(n=21)$ e HM $(n=11)$ ] e atividade basal do nervo simpático torácico [(\%tSNA, painel $B$, camundongos do grupo controle $(n=16)$ e HM ( $n=10)$ ] durante a fase inspiratória (Insp), post-inspiração (Pós-l) e expiração final (E2) dos grupos controle e HM (painel A). * Diferente entre fases do mesmo grupo. \# diferente em relação ao grupo controle $(p<0,05)$. ANOVA de uma via para comparar fases no mesmo grupo e ANOVA de duas vias para comparar as diferenças entre os grupos. 


\subsection{Bradicardia e simpato-excitação em resposta à ativação do} quimiorreflexo periférico na preparação in situ de camundongos controle e HM.

As magnitudes das respostas de bradicardia em resposta à ativação do quimiorreflexo nos camundongos $\mathrm{HM}(\mathrm{n}=10)$ não foram diferentes em relação aos camundongos controle $[n=12$, Figura 8 ( $-195 \pm 134$ vs $-267 \pm 110$ bpm, $P=0,1898$, Figura 9, painel A)]. As magnitudes das alterações na atividade tSN em resposta a ativação do quimiorreflexo em camundongos $\mathrm{HM}(\mathrm{n}=9)$ não foram diferentes em relação aos camundongos controle [ $\mathrm{n}=15$, Figura $8(26,0 \pm 8,1$ vs $31,5 \pm 7,7 \%$, $P=0,1189$, Figura 9, painel $B$ )]. As frequências de disparos do nervo frênico (DNF) em resposta à ativação do quimiorreflexo nos camundongos $\mathrm{HM}(\mathrm{n}=11)$ não foram diferentes em relação aos camundongos controle [n=20, Figura $8(1,42 \pm 0,52$ vs $1,48 \pm 0,58 \mathrm{~Hz}, P=0,9889$, Figura 9, painel $\mathrm{C})]$. As magnitudes das alterações na atividade do nervo abdominal (Abd) em resposta à ativação do quimiorreflexo em camundongos $H M(n=9)$ não foram diferentes em relação aos camundongos controle [ $\mathrm{n}=17$, Figura $8(24,7 \pm 7,1$ vs $23,9 \pm 7,4 \%, P=0,9915$, Figura 9, painel $\mathrm{D})]$. 

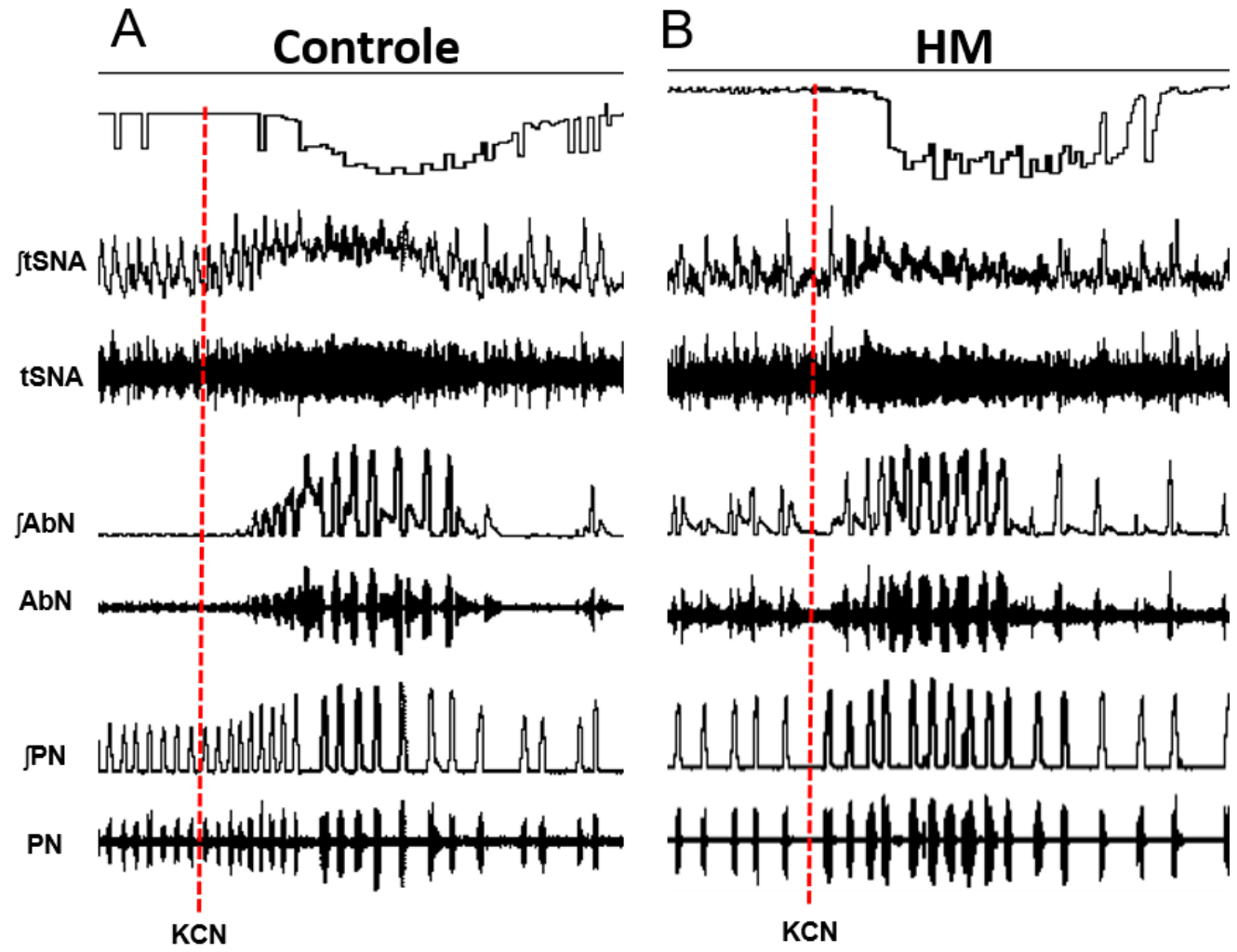

Figura 8: Traçados representativos dos registros da frequência cardíaca e dos registros dos nervos autonômicos e respiratórios na preparação in situ de camundongos controle e HM durante o estímulo do quimiorreflexo periférico. Traçados representativos de preparações in situ de um camundongo controle (painel A) e um camundongo HM (painel B) mostrando a frequência cardíaca basal (FC), e atividades bruta e integrada ( $(\delta)$ dos nervos simpático torácico (tSN), nervo abdominal $(A b N)$ e nervo frênico (NF). A linha tracejada vermelha marca o momento da injeção de $\mathrm{KCN}(20 \mu \mathrm{g} / 50 \mu \mathrm{L})$. 
A

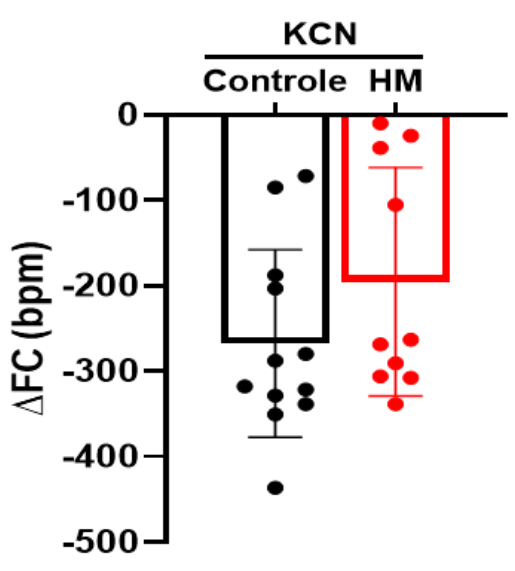

C

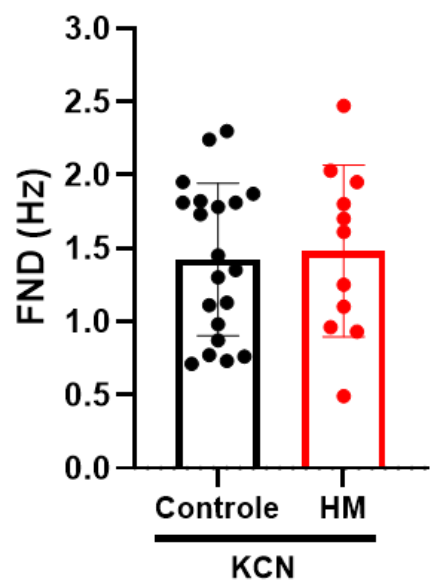

B

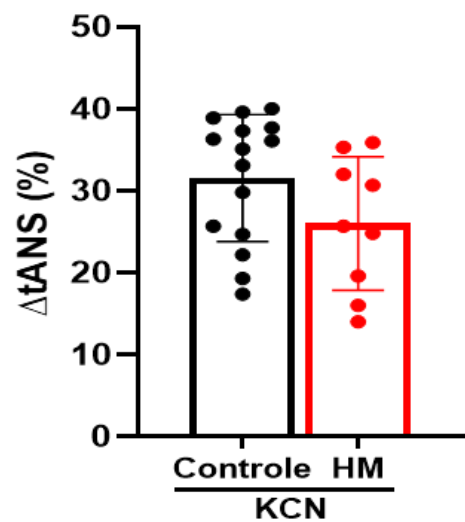

D

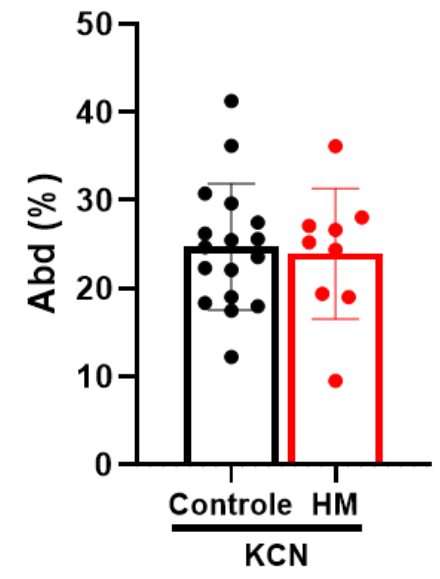

Figura 9: Valores médios das respostas de bradicardia, autonômica simpática e respiratórias em resposta à ativação ao quimiorreflexo periférico na preparação in situ do grupo controle e $H M$. Alterações na frequência cardíaca $(\triangle F C$, painel $A)$ de camundongos do grupo controle $(n=12)$ e HM $(n=10)$. Atividade do nervo torácico simpático (tSNA, $\triangle \%$, painel $B$ ) de camundongos do grupo controle $(n=15)$ e $H M(n=9)$ em resposta a ativação do quimiorreflexo periférico. Frequência de disparo do nervo frênico (DNF, Hz, painel C) de camundongos do grupo controle $(n=20)$ e HM $(n=11)$ em resposta a ativação do quimiorreflexo periférico. Atividade do nervo abdominal (Abd, \%, painel $D$ ) de camundongos do grupo controle $(n=17)$ e HM $(n=9)$ em resposta a ativação do quimiorreflexo periférico. Comparação estatística feita por meio do teste t de Student não pareado). 
Discussão 


\section{DISCUSSÃO}

Estudos anteriores do nosso laboratório realizados ratos jovens mostraram que à $\mathrm{HM}$ altera o acoplamento simpático-respiratório, promovendo um aumento da atividade simpática e consequentemente um quadro hipertensivo nestes animais (MORAES et al., 2014; ACCORSI-MENDONÇA et al., 2015; MACHADO et al., 2017). Estudos recentes do nosso laboratório mostraram que os camundongos submetidos à $H M$, diferente dos ratos, além de não apresentarem elevação significativa da pressão arterial, apresentaram uma redução significativa na frequência cardíaca basal (RODRIGUES \& SOUZA et al, 2021). Nestes estudos realizados em camundongos HM acordados foi também observado um aumento significativo na magnitude das respostas de bradicardia frente à ativação do quimiorreflexo feita por meio da administração intravenosa de KCN (RODRIGUES \& SOUZA et al, 2021). Dessa forma, os estudos realizados no contexto da presente dissertação tiveram como principal objetivo caracterizar as possíveis alterações no acoplamento autonômico e respiratório em camundongos submetidos à HM. Para atingir esse objetivo, utilizamos a preparação in situ coração-tronco encefálico isolados a partir da qual realizamos diversas análises, de forma bastante criteriosa, das atividades de nervos autonômicos (cVN e tSN) e respiratórios ( $\mathrm{NF}, \mathrm{AbN}$ e cVN) de camundongos controle e HM.

Na preparação in situ também registramos a FC basal, a qual não foi diferente entre os grupos controle e HM. Vale ressaltar que nos camundongos acordados e com livre movimentação a $\mathrm{FC}$ basal foi significativamente menor no grupo $\mathrm{HM}$ (RODRIGUES \& SOUZA et al, 2021). Importante também destacar que a FC basal registrada nos camundongos controle e $\mathrm{HM}$ acordados e com livre movimentação foi muito mais elevada quando comparada à $F C$ basal dos mesmos grupos experimentais registrada na preparação in situ (RODRIGUES \& SOUZA et al, 2021). Essa diferença provavelmente está relacionada ao fato de que a FC registrada na preparação in situ corresponde à frequência intrínseca do marcapasso cardíaco, uma vez que devido à baixa pressão de perfusão, os barorreceptores arteriais estão desativados. Portanto, o fato da FC basal ser semelhante nos camundongos controle e HM na preparação in situ indica que a HM não alterou a frequência intrínseca do marcapasso desses animais. A diferença 
observada entre a FC basal nos camundongos controle nas condições in vivo e in situ pode estar relacionada a uma predominância do componente simpático cardíaco nos camundongos in vivo. Por outro lado, a redução da FC basal nos camundongos HM in vivo, como descrito acima, sugere uma predominância do componente parassimpático nesses animais como decorrência da HM. Essas alterações indicam que a HM promove uma importante alteração no balanço autonômico para o coração, a qual pode contribuir para explicar, pelo menos em parte, por que a magnitude da bradicardia em resposta à ativação do quimiorreflexo in vivo foi maior do que nas preparações in situ (RODRIGUES \& SOUZA et al, 2021).

Nas análises dos registros dos nervos respiratórios nas preparações in situ de camundongos controle nós verificamos que o padrão respiratório eupneico registrado estava de acordo com o padrão descrito anteriormente, com os seguintes destaques: a) frequência de disparo basal do nervo frênico (NF) maior do que nos ratos, b) atividade em rampa do NF (inspiração), c) padrão bifásico da atividade cVN caracterizada por um aumento da amplitude durante as fases Insp e Pós-I, seguida por uma redução e inatividade durante a fase E2; e d) a fase pré-I corresponde ao período entre o início da elevação da atividade vagal e o início da atividade em rampa do NF (PATON, 1996a; PATON, 1996b; PATON \& BUTCHER,1998; STETTNER et al, 2007; 2008; SMITH et al., 2007). O conjunto desses estudos anteriores combinados com os resultados obtidos por nós no presente trabalho documentam um padrão motor eupneico na preparação in situ de camundongos. Além disso, o padrão respiratório registrado por nós em preparações in situ de camundongos adultos está de acordo com estudos mostrando que o padrão respiratório do camundongo é composto pelas seguintes fases: Pré-I, Insp, Pós-I e E2 (PATON \& RICHTER, 1995; PATON, 1996a; PATON, 1996b).

Os registros dos nervos respiratórios mostraram que as principais alterações induzidas pela $\mathrm{HM}$ foram uma significante redução na frequência basal de disparo do nervo frênico (DNF) e um aumento na duração da expiração total devido ao aumento na duração das fases Pós-l e Pré-l. Por estas razões os camundongos submetidos à $\mathrm{HM}$ apresentaram ciclos respiratórios muito mais longos do que os camundongos do grupo controle. Considerando o aumento significativo na 
atividade cVN observado durante a fase Pós-I no grupo HM, nós sugerimos que as alterações do componente vagal que controlam as vias aéreas superiores podem estar contribuindo para esta maior duração da expiração. Neste contexto, nós também observamos um aumento significativo da incidência de eventos Late- $E$ na atividade $\mathrm{AbN}$ dos camundongos $\mathrm{HM}$ em relação aos camundongos do grupo controle. Nesse caso, nós sugerimos que o aumento da incidência de eventos LateE está relacionado a um aumento do volume corrente devido ao recrutamento do volume de reserva expiratório, na tentativa de aumentar a eficiência das trocas gasosas, como observado nos camundongos HM in vivo (RODRIGUES \& SOUZA et al, 2021). Vale ressaltar que alterações semelhantes foram observadas em estudos anteriores que exploraram situações de hipóxia ou hipercapnia em ratos (ZOCCAL et al., 2008, 2009; ABDALA et al, 2009; ZOCCAL \& MACHADO, 2010; MORAES et al., 2013; MORAES et al., 2014; FLOR et al., 2018).

No presente estudo, observamos que os camundongos submetidos a preparação in situ apresentam uma redução da frequência de DNF quando expostos a HM. Sugerimos que essa alteração do padrão respiratório é decorrente ao aumento da fase expiratória total, o qual ocorre devido ao aumento da duração das fases Pós-I e Pré-I. Além disso, concomitantemente observamos um aumento da atividade cVN durante a fase Pós-I, a qual está relacionada com a modulação da resistência das vias aéreas superiores. Tendo em vista a redução mantida do $\mathrm{O}_{2}$ na $\mathrm{HM}$, podemos sugerir que o aumento da atividade cVN se caracteriza como uma compensação com a finalidade de proporcionar mais tempo às trocas gasosas, tornando este processo mais eficiente para o reestabelecimento da homeostase (SHIBA et al. 1999; DUTSCHMANN \& PATON, 2002; KUBIN et al, 2006; SMITH et al., 2007; MÖRSCHEL \& DUTSCHMANN, 2009). Neste sentido, o aumento do tempo de expiração (principalmente da fase Pós-I e Pré-I) e da atividade cVN na preparação in situ de camundongos HM poderiam estar relacionadas a redução da frequência de DNF observada no presente trabalho.

Com relação aos parâmetros respiratórios registrados em animais acordados e com livre movimentação, observamos que camundongos submetidos à HM apresentam aumento significativo na frequência respiratória $\left(f_{R}\right)$, volume corrente $\left(\mathrm{V}_{T}\right)$ e ventilação pulmonar [( $\left.\mathrm{V}_{\mathrm{E}}\right)$ RODRIGUES \& SOUZA et al, 2021]. Essas alterações observadas em camundongos acordados e com livre movimentação são 
semelhantes àquelas observadas em ratos jovens submetidos à HM (DA SILVA et al., 2019; FLOR et al, 2018; BAZILIO et al., 2021). Esses resultados também estão de acordo com aqueles descritos em estudos anteriores que mostraram aumento semelhante em todos estes parâmetros ventilatórios ( $f_{R}, V_{T}$ e $V_{E}$ ) em resposta a desafios hipóxicos em camundongos (TANKERSLEY et al., 2000; HAN et al., 2001; CRAMER et al., 2015; LEE \& LIAO, 2018; GIANNAKOPOULOU et al., 2019). Além disso, há evidências de que a exposição à HM promove um aumento progressivo na ventilação basal em mamíferos, o qual pode persistir por horas ou dias após a reoxigenação (POWELL et al. 1998). Esta resposta ventilatória à HM está relacionada aos aumentos nas atividades motoras inspiratórias e expiratórias que elevam tanto a $f_{\mathrm{R}}$ quanto o $\mathrm{V}_{\mathrm{T}}$ (MATEIKA et al., 1996; LEMES \& ZOCCAL, 2014). Estudos de Flor et al, (2018) mostraram que à HM de $24 \mathrm{~h}$ foi suficiente para elevar a ventilação basal em ratos jovens e que estes animais exibiram maior $f_{R}$ e $V_{T}$. Os autores sugeriram que este aumento na ventilação em repouso dos ratos HM in vivo está relacionada com as alterações do padrão respiratório, incluindo a expiração ativa, observadas na preparação in situ de animais submetidos ao mesmo protocolo experimental (FLOR et al, 2018). Nesse cenário, os nossos resultados obtidos em camundongos submetidos à $\mathrm{HM}$ foram similares àqueles observados em ratos submetidos ao mesmo protocolo de hipóxia. A partir desse conjunto de observações, nós sugerimos que os aumentos observados nos parâmetros ventilatórios de camundongos submetidos à $\mathrm{HM}$ in vivo tem como finalidade reestabelecer $\mathrm{PaO}_{2}$ (RODRIGUES \& SOUZA et al, 2021).

Os registros dos nervos respiratórios na preparação in situ também mostraram uma redução significativa na frequência basal de disparos do nervo frênico em camundongos HM, a qual é diferente em relação à elevada frequência respiratória observada nesses animais in vivo. Podemos sugerir que essa diferença está associada tanto à decorticação quanto à ausência de algumas vias de feedback periféricos, como a via sensorial dos receptores de estiramento pulmonar (reflexo de Hering-Breuer) decorrente da retirada dos pulmões na preparação in situ (ZOCCAL et al., 2009). Vale ressaltar que há evidências de que este sistema sensorial contribui para o controle da frequência respiratória (MÖRSCHEL \& DUTSCHMANN, 2009; LEMES \& ZOCCAL, 2014), uma vez que a sua integridade previne a expansão pulmonar excessiva, modula a duração da atividade 
inspiratória e controla a transição entre as fases inspiratória e expiratória (KUBIN et al., 2006; MÖRSCHEL \& DUTSCHMANN, 2009; LEMES \& ZOCCAL, 2014).

As atividades $\mathrm{cVN}$ e tSN também foram analisadas durante a fase expiratória prolongada com a finalidade de avaliarmos possíveis alterações nos acoplamentos simpático/respiratório e parassimpático/respiratório, os quais poderiam influenciar os parâmetros cardiovasculares observados em camundongos HM acordados (RODRIGUES \& SOUZA et al, 2021). O padrão da atividade $c V N$ de camundongos mostra um componente inspiratório simultaneamente ao disparo do NF e um componente Pós-I (SMITH et al., 2007; STETTNER et al, 2007; 2008). No entanto, a fase Pós-I foi significativamente mais longa em camundongos $\mathrm{HM}$ do que em camundongos do grupo controle, indicando um aumento na atividade vagal durante esta fase do ciclo respiratório. Considerando que a atividade cVN também controla a resistência das vias aéreas superiores, sugerimos que a fase Pós-I mais longa, simultaneamente com a atividade aumentada $\mathrm{cVN}$, tem como objetivo aumentar a resistência das vias aéreas superiores ao fluxo de ar expiratório, com a finalidade de prolongar e facilitar as trocas gasosas e tornar este processo mais eficiente sob uma condição de HM (SHIBA et al. 1999; DUTSCHMANN \& PATON, 2002; KUBIN et al, 2006; SMITH et al., 2007; MÖRSCHEL \& DUTSCHMANN, 2009). Além disso, esse possível mecanismo facilitador das trocas gasosas também é observado no aumento da duração da fase Pré-I, a qual se correlaciona com uma exagerada abdução da glote na fase pré-inspiratória. Esse fenômeno parece ocorrer em situações de desafios respiratórios e a sua ativação parece promover uma saída controlada de ar durante a expiração ativa (eventos Late-E), aumentando assim o período de tempo para que ocorram as trocas gasosas ao nível dos alvéolos (ABDALA et al, 2009; MORAES et al, 2014; MORAES \& MACHADO, 2015).

Em relação à atividade $\mathrm{tSN}$, tanto camundongos controle quanto $\mathrm{HM}$ apresentaram o pico da atividade durante a fase Pós-l e baixa amplitude na fase expiratória final (E2). Esse padrão de atividade tSN observado nos camundongos é similar aquele descrito em ratos, nos quais a atividade simpática se apresentou sincronizada com a atividade respiratória com pico durante o início da pós inspiração ou o início da expiração (HASELTON \& GUYENET, 1989; MALPAS, 1998; ZOCCAL et al., 2008; MACHADO et al., 2017). Em ratos submetidos à HM foram observados expiração ativa e eventos Late-E na atividade do $A b N$, os quais 
ocorreram simultaneamente aos picos adicionais na atividade do tSN no final da fase E2 (ZOCCAL et al., 2008, 2009; ZOCCAL \& MACHADO, 2010, 2011; MORAES et al., 2012, 2014, 2016; ACCORSI-MENDONÇA et al., 2015; MACHADO et al., 2017; FLOR et al., 2018). As análises dos nossos registros mostraram que a atividade basal do $\mathrm{tSN}$ em camundongos submetidos à $\mathrm{HM}$ foi reduzida durante a fase E2, e não foram observadas alterações durante as fases Insp e Pós-l.

Tendo em vista os achados descritos acima, vale destacar aqui as principais diferenças observadas no acoplamento simpático-respiratório em ratos quando comparados aos camundongos submetidos à HM. Em estudos realizados anteriormente no nosso laboratório em ratos submetidos à $\mathrm{HM}$, foi documentada uma alteração importante no acoplamento simpático-respiratório, com a elevada incidência de eventos Late-E na atividade do AbN. Estas alterações indicam claramente a expressão da expiração ativa nesses animais, a qual se correlaciona com a hiperatividade simpática e consequentemente com a hipertensão arterial observada nos ratos submetidos à HM (MORAES et al, 2014; ACCORSIMENDONÇA et al., 2015). Nos camundongos submetidos à HM nós estamos mostrando que a elevada incidência de eventos Late-E pelo AbN é acompanhada por uma redução na atividade simpática e um grande aumento na atividade parassimpática, o que revela uma notável diferença nas respostas autonômicas e respiratórias entre ratos e camundongos quando submetidos à $\mathrm{HM}$.

Há evidências experimentais de que a expiração ativa em ratos é gerada pelo grupo respiratório parafacial ( $\mathrm{pFRG}$ ) com consequente aumento da atividade simpática (MACHADO et al., 2017; PISANSKI \& PAGLIARDINI, 2018). Os resultados obtidos em camundongos submetidos à $\mathrm{HM}$ nos permitem sugerir que a expiração ativa, a qual não é acompanhada de aumento da atividade simpática, é mediada de forma diferente pelo $\mathrm{pFRG}$ ou por algum outro grupamento neuronal do tronco encefálico. Nessas duas possibilidades a modulação da expiração ativa, de acordo com o observado, não implica em um aumento da atividade autonômica simpática e isso poderia explicar, pelo menos em parte, a não elevação da pressão arterial nos camundongos submetidos à HM. 
Neste contexto, sugerimos que as alterações respiratórias observadas em camundongos submetidos à HM estão induzindo um desbalanço autonômico em favor do componente autonômico parassimpático, o que poderia contribuir para prevenir a elevação da pressão arterial, uma vez que os camundongos HM acordados e com livre movimentação apresentaram uma significativa redução na frequência cardíaca basal, o que por sua vez provavelmente se reflete numa diminuição do débito cardíaco (RODRIGUES \& SOUZA et al, 2021). Além disso, os nossos resultados estão mostrando que camundongos submetidos à $\mathrm{HM}$ apresentam significativa redução da atividade do tSN durante a fase E2, o que poderia também contribuir para evitar o desenvolvimento de hipertensão arterial nos camundongos submetidos à $\mathrm{HM}$. 
Considerações finais 


\section{CONSIDERAÇÕES FINAIS}

Camundongos submetidos à $\mathrm{HM}$ apresentam um desbalanço autonômico favorável ao componente parassimpático, o que poderia explicar as alterações observadas nos padrões autonômicos e respiratórios na preparação in situ, as quais são diferentes daquelas observadas nos ratos submetidos à $H M$. Os nossos resultados indicam que os camundongos $\mathrm{HM}$ constituem um modelo experimental muito importante para o melhor entendimento de como as mudanças no padrão respiratório podem modular os componentes simpático e parassimpático e, desta forma, contribuir para a manutenção da pressão arterial dentro de uma faixa normal de variação mesmo em situações de desafios hipóxicos, como é o caso da HM. 
Referências bibliográficas 


\section{REFERÊNCIAS BIBLIOGRAFICAS}

ABBOUD, Francois M. et al. Reflex control of the peripheral circulation. Progress in cardiovascular diseases, v. 18, n. 5, p. 371-403, 1976.

ABDALA, A. P. L. et al. Abdominal expiratory activity in the rat brainstem-spinal cord in situ: patterns, origins and implications for respiratory rhythm generation. The Journal of physiology, v. 587, n. 14, p. 3539-3559, 2009.

ACCORSI-MENDONÇA, Daniela et al. Enhanced firing in NTS induced by short-term sustained hypoxia is modulated by glia-neuron interaction. Journal of Neuroscience, v. 35, n. 17, p. 6903-6917, 2015.

AICHER, Sue A. et al. Monosynaptic projections from the nucleus tractus solitarii to C1 adrenergic neurons in the rostral ventrolateral medulla: comparison with input from the caudal ventrolateral medulla. Journal of Comparative Neurology, v. 373, n. 1, p. 62-75, 1996.

ALLWOOD, Melissa A. et al. Moderate and severe hypoxia elicit divergent effects on cardiovascular function and physiological rhythms. The Journal of physiology, $v$. 596, n. 15, p. 3391-3410, 2018.

ANTUNES, Vagner R.; BRAGA, Valdir A.; MACHADO, Benedito H. Autonomic and respiratory responses to microinjection of ATP into the intermediate or caudal nucleus tractus solitarius in the working heart-brainstem preparation of the rat. Clinical and experimental pharmacology and physiology, v. 32, n. 5-6, p. 467-472, 2005.

BARRETT, Karlene T. et al. Impaired neonatal cardiorespiratory responses to hypoxia in mice lacking PAC1 or VPAC2 receptors. American Journal of Physiology-Regulatory, Integrative and Comparative Physiology, v. 316, n. 5, p. R594-R606, 2019.

BARROS, Renata $\mathrm{CH}$ et al. Cardiovascular responses to chemoreflex activation with potassium cyanide or hypoxic hypoxia in awake rats. Autonomic Neuroscience, v. 97, n. 2, p. 110-115, 2002.

BAZILIO, Darlan S. et al. Distinct cardiovascular and respiratory responses to shortterm sustained hypoxia in juvenile Sprague Dawley and Wistar Hannover rats. Autonomic Neuroscience, v. 230, p. 102746, 2021.

BISCOE, Tj.; DUCHEN, Mr. Monitoring PO2 by the Carotid Chemoreceptor. Physiology, v. 5, n. 6, p. 229-233, 1 dez. 1990. 
BRAGA, Valdir A. et al. Cardiovascular responses to peripheral chemoreflex activation and comparison of different methods to evaluate baroreflex gain in conscious mice using telemetry. American Journal of Physiology-Regulatory, Integrative and Comparative Physiology, v. 295, n. 4, p. R1168-R1174, 2008.

BRAGA, Valdir A. et al. Involvement of I-glutamate and ATP in the neurotransmission of the sympathoexcitatory component of the chemoreflex in the commissural nucleus tractus solitarii of awake rats and in the working heart-brainstem preparation. The Journal of physiology, v. 581, n. 3, p. 1129-1145, 2007.

BRAGA, Valdir A.; SORIANO, Renato N.; MACHADO, Benedito $\mathrm{H}$. Sympathoexcitatory response to peripheral chemoreflex activation is enhanced in juvenile rats exposed to chronic intermittent hypoxia. Experimental physiology, v. 91, n. 6 , p. 1025-1031, 2006.

CALBET, J. A L. Chronic hypoxia increases blood pressure and noradrenaline spillover in healthy humans. The Journal Of Physiology, v. 551, n. 1, p. 379-386, 4 jul. 2003.

CAMPEN, M. J.; SHIMODA, L. A.; O'DONNELL, C. P.. Acute and chronic cardiovascular effects of intermittent hypoxia in C57BL/6J mice. Journal Of Applied Physiology, v. 99, n. 5, p. 2028-2035, nov. 2005.

CAMPEN, Matthew J. et al. Phenotypic variation in cardiovascular responses to acute hypoxic and hypercapnic exposure in mice. Physiological Genomics, v. 20, n. 1, p. 15-20, 2004.

CANNON, Walter B. Organization for physiological homeostasis. Physiological reviews, v. 9, n. 3, p. 399-431, 1929.

$\mathrm{CHU}$, Alison et al. Cardiovascular dysfunction in adult mice following postnatal intermittent hypoxia. Pediatric research, v. 77, n. 3, p. 425-433, 2015.

COOPER, Steven J. From Claude Bernard to Walter Cannon. Emergence of the concept of homeostasis. Appetite, v. 51, n. 3, p. 419-427, 2008.

COSTA, Kauê M. et al. Evolution and physiology of neural oxygen sensing. Frontiers in physiology, v. 5, p. 302, 2014.

DA SILVA, Melina P. et al. Hyperexcitability and plasticity induced by sustained hypoxia on rectus abdominis motoneurons. The Journal of physiology, v. 597, n. 7, p. 1935-1956, 2019.

DEMATTEIS, Maurice et al. Intermittent hypoxia induces early functional cardiovascular remodeling in mice. American journal of respiratory and critical care medicine, v. 177, n. 2, p. 227-235, 2008. 
DEMPSEY, J. A. et al. Dempsey JA, Veasey SC, Morgan BJ, O'Donnell CP. Pathophysiology of Sleep Apnea. Physiol Rev 90: 47-112, 2010. Physiological reviews, v. 90, n. 2, p. 797-798, 2010.

DUTSCHMANN, M.; PATON, J. F. R. Glycinergic inhibition is essential for coordinating cranial and spinal respiratory motor outputs in the neonatal rat. The Journal of physiology, v. 543, n. 2, p. 643-653, 2002.

FELDMAN, J. L.; MCCRIMMON, D. R. Neural control of breathing. In: Fundamental Neuroscience, 3rd edition. Academic Press, 2008. p. 855-872.

FLOR, Karine C. et al. Short-term sustained hypoxia elevates basal and hypoxiainduced ventilation but not the carotid body chemoreceptor activity in rats. Frontiers in physiology, v. 9, p. 134, 2018.

FRANCHINI, Kleber G.; KRIEGER, Eduardo M. Cardiovascular responses of conscious rats to carotid body chemoreceptor stimulation by intravenous KCN. Journal of the autonomic nervous system, v. 42, n. 1, p. 63-69, 1993.

GIANNAKOPOULOU, Charoula Eleni et al. Regulation of breathing pattern by IL10. American Journal of Physiology-Regulatory, Integrative and Comparative Physiology, v. 317, n. 1, p. R190-R202, 2019.

GRANATA, Antonio R.. Rostral ventrolateral medulla descending neurons excited by nucleus tractus solitarii inputs. Brain Research, v. 648, n. 2, p. 299-305, jun. 1994.

HAN, Fang; STROHL, Kingman P. Inheritance of ventilatory behavior in rodent models. Respiration physiology, v. 121, n. 2-3, p. 247-256, 2000.

HANSEN, Jim; SANDER, Mikael. Sympathetic neural overactivity in healthy humans after prolonged exposure to hypobaric hypoxia. The Journal Of Physiology, v. 546, n. 3, p. 921-929, fev. 2003.

HASELTON, J. R.; GUYENET, P. G. Central respiratory modulation of medullary sympathoexcitatory neurons in rat. American Journal of Physiology-Regulatory, Integrative and Comparative Physiology, v. 256, n. 3, p. R739-R750, 1989.

ISHIGURO, Takashi et al. Impaired ventilation and metabolism response to hypoxia in histamine $\mathrm{H} 1$ receptor-knockout mice. Respiratory physiology \& neurobiology, v. 154, n. 3, p. 331-341, 2006.

KARA, T.; NARKIEWICZ, K.; SOMERS, V. K. Chemoreflexes - physiology and clinical implications. Acta Physiologica Scandinavica, v. 177, n. 3, p. 377-384, 28 fev. 2003. 
KUBIN, Leszek et al. Central pathways of pulmonary and lower airway vagal afferents. Journal of Applied Physiology, v. 101, n. 2, p. 618-627, 2006.

LEE, Kun-Ze; LIAO, Wenlin. Loss of CDKL5 disrupts respiratory function in mice. Respiratory Physiology \& Neurobiology, v. 248, p. 48-54, jan. 2018.

LEMES, Eduardo V.; ZOCCAL, Daniel B. Vagal afferent control of abdominal expiratory activity in response to hypoxia and hypercapnia in rats. Respiratory physiology \& neurobiology, v. 203, p. 90-97, 2014.

LIN, Min et al. Chronic intermittent hypoxia impairs baroreflex control of heart rate but enhances heart rate responses to vagal efferent stimulation in anesthetized mice. American Journal of Physiology-Heart and Circulatory Physiology, v. 293, n. 2, p. H997-H1006, 2007.

MACHADO, Benedito H. Neurotransmission of the Cardiovascular Reflexes in the Nucleus Tractus Solitarii of Awake Rats. Annals Of The New York Academy Of Sciences, v. 940, n. 1, p. 179-196, 25 jun. 2001.

MACHADO, Benedito H.; ZOCCAL, Daniel B.; MORAES, Davi J. A.. Neurogenic hypertension and the secrets of respiration. American Journal Of PhysiologyRegulatory, Integrative And Comparative Physiology, v. 312, n. 6, p. 864-872, 1 jun. 2017.

MALPAS, Simon C. The rhythmicity of sympathetic nerve activity. Progress in neurobiology, v. 56, n. 1, p. 65-96, 1998.

MANCIA, G. et al. Reflex cardiovascular regulation in humans. Journal of cardiovascular pharmacology, v. 7, p. S152-9, 1985.

MATEIKA, J. H.; ESSIF, E.; FREGOSI, R. F. Effect of hypoxia on abdominal motor unit activities in spontaneously breathing cats. Journal of Applied Physiology, v. 81, n. 6, p. 2428-2435, 1996.

MODELL, Harold et al. A physiologist's view of homeostasis. Advances in physiology education, v. 39, n. 4, p. 259-266, 2015.

MOLKOV, Yaroslav I. et al. Intermittent hypoxia-induced sensitization of central chemoreceptors contributes to sympathetic nerve activity during late expiration in rats. Journal of neurophysiology, v. 105, n. 6, p. 3080-3091, 2011.

MORAES, Davi JA et al. Electrophysiological properties of rostral ventrolateral medulla presympathetic neurons modulated by the respiratory network in rats. Journal of Neuroscience, v. 33, n. 49, p. 19223-19237, 2013.

MORAES, Davi JA et al. Modulation of respiratory responses to chemoreflex activation by L-glutamate and ATP in the rostral ventrolateral medulla of awake 
rats. American Journal of Physiology-Regulatory, Integrative and Comparative Physiology, v. 300, n. 6, p. R1476-R1486, 2011.

MORAES, Davi JA et al. Respiratory network enhances the sympathoinhibitory component of baroreflex of rats submitted to chronic intermittent hypoxia. Hypertension, v. 68, n. 4, p. 1021-1030, 2016.

MORAES, Davi JA et al. Short-term sustained hypoxia induces changes in the coupling of sympathetic and respiratory activities in rats. The Journal of physiology, v. 592, n. 9, p. 2013-2033, 2014.

MORAES, Davi JA; MACHADO, Benedito H. Electrophysiological properties of laryngeal motoneurones in rats submitted to chronic intermittent hypoxia. The Journal of physiology, v. 593, n. 3, p. 619-634, 2015.

MORAES, Davi JA; MACHADO, Benedito H.; PATON, Julian FR. Carotid body overactivity induces respiratory neurone channelopathy contributing to neurogenic hypertension. The Journal of physiology, v. 593, n. 14, p. 3055-3063, 2015.

MORAES, Davi JA; ZOCCAL, Daniel B.; MACHADO, Benedito H. Medullary respiratory network drives sympathetic overactivity and hypertension in rats submitted to chronic intermittent hypoxia. Hypertension, v. 60, n. 6, p. 1374-1380, 2012.

MORAES, Davi JA; ZOCCAL, Daniel B.; MACHADO, Benedito H. Sympathoexcitation during chemoreflex active expiration is mediated by L-glutamate in the RVLM/Bötzinger complex of rats. Journal of neurophysiology, v. 108, n. 2, p. 610-623, 2012.

MORAES, Davi JA; ZOCCAL, Daniel B.; MACHADO, Benedito H. Sympathoexcitation during chemoreflex active expiration is mediated by L-glutamate in the RVLM/Bötzinger complex of rats. Journal of neurophysiology, v. 108, n. 2, p. 610-623, 2012.

MOREIRA, Tiago S. et al. Central chemoreceptors and neural mechanisms of cardiorespiratory control. Brazilian Journal Of Medical And Biological Research, v. 44, n. 9, p. 883-889, set. 2011.

MÖRSCHEL, Michael; DUTSCHMANN, Mathias. Pontine respiratory activity involved in inspiratory/expiratory phase transition. Philosophical Transactions of the Royal Society B: Biological Sciences, v. 364, n. 1529, p. 2517-2526, 2009.

PADLEY, James R. et al. Central command regulation of circulatory function mediated by descending pontine cholinergic inputs to sympathoexcitatory rostral ventrolateral medulla neurons. Circulation research, v. 100, n. 2, p. 284-291, 2007. 
PALAPARTHI, Sarvani. Role of Homeostasis in Human Physiology: A Review. J Med Physiol Ther 1:101, 2017.

PAN, Wanying et al. Dose response of dexmedetomidine-induced resistance to hypoxia in mice. Molecular medicine reports, v. 14, n. 4, p. 3237-3242, 2016.

PATON, J. F. R.; LI, Y.-W.; KASPAROV, S. Reflex response and convergence of pharyngoesophageal and peripheral chemoreceptors in the nucleus of the solitary tract. Neuroscience, v. 93, n. 1, p. 143-154, 1999.

PATON, J. F. The ventral medullary respiratory network of the mature mouse studied in a working heart-brainstem preparation. The Journal of physiology, v. 493, n. 3 , p. 819-831, 1996b.

PATON, Julian FR et al. Sensory afferent selective role of P2 receptors in the nucleus tractus solitarii for mediating the cardiac component of the peripheral chemoreceptor reflex in rats. The Journal of physiology, v. 543, n. 3, p. 995-1005, 2002.

PATON, Julian FR. A working heart-brainstem preparation of the mouse. Journal of neuroscience methods, v. 65, n. 1, p. 63-68, 1996a.

PATON, Julian FR; BUTCHER, James W. Cardiorespiratory reflexes in mice. Journal of the autonomic nervous system, v. 68, n. 1-2, p. 115-124, 1998.

PATON, Julian FR; RICHTER, Diethelm W. Maturational changes in the respiratory rhythm generator of the mouse. Pflügers Archiv, v. 430, n. 1, p. 115-124, 1995.

PEARSON, James T. et al. a 2-Adrenoreceptor mediated sympathoinhibition of heart rate during acute hypoxia is diminished in conscious prostacyclin synthase deficient mice. Pflügers Archiv-European Journal of Physiology, v. 454, n. 1, p. 29-39, 2007.

PENG, Ying-Jie et al. Heterozygous HIF-1a deficiency impairs carotid body-mediated systemic responses and reactive oxygen species generation in mice exposed to intermittent hypoxia. The Journal of physiology, v. 577, n. 2, p. 705-716, 2006.

PISANSKI, Annette; PAGLIARDINI, Silvia. The parafacial respiratory group and the control of active expiration. Respiratory physiology \& neurobiology, v. 265, p. 153-160, 2019.

POWELL, F.L; MILSOM, W.K; MITCHELL, G.S. Time domains of the hypoxic ventilatory response. Respiration Physiology, v. 112, n. 2, p. 123-134, maio 1998.

POWELL, Frank L.. The influence of chronic hypoxia upon chemoreception. Respiratory Physiology \& Neurobiology, v. 157, n. 1, p. 154-161, jul. 2007. 
RICHTER, Diethelm W.; SMITH, Jeffrey C. Respiratory rhythm generation in vivo. Physiology, v. 29, n. 1, p. 58-71, 2014.

RODOLFO K. What is homeostasis? Sci Am. 2000;1-10.

RODRIGUES, Karla L. et al. Changes in the autonomic and respiratory patterns in mice submitted to short-term sustained hypoxia. Experimental Physiology, v. 106, n. 3, p. 759-770, 2021.

ROSS, Christopher A.; RUGGIERO, David A.; REIS, Donald J.. Projections from the nucleus tractus solitarii to the rostral ventrolateral medulla. The Journal Of Comparative Neurology, v. 242, n. 4, p. 511-534, 22 dez. 1985.

SCHWENKE, Daryl O. et al. Long-term monitoring of pulmonary arterial pressure in conscious, unrestrained mice. Journal of pharmacological and toxicological methods, v. 53, n. 3, p. 277-283, 2006.

SHIBA, Keisuke et al. Multifunctional laryngeal motoneurons: an intracellular study in the cat. Journal of Neuroscience, v. 19, n. 7, p. 2717-2727, 1999.

SMITH, Jeffrey C. et al. Spatial and functional architecture of the mammalian brain stem respiratory network: a hierarchy of three oscillatory mechanisms. Journal of neurophysiology, v. 98, n. 6, p. 3370-3387, 2007.

SMITH, Orville A. Reflex and central mechanisms involved in the control of the heart and circulation. Annual Review of Physiology, v. 36, n. 1, p. 93-123, 1974.

STETTNER, Georg M. et al. Breathing dysfunctions associated with impaired control of postinspiratory activity in Mecp2-/y knockout mice. The Journal of physiology, $v$. 579, n. 3, p. 863-876, 2007.

STETTNER, Georg M. et al. Hypoxic and hypercapnic challenges unveil respiratory vulnerability of Surf1 knockout mice, an animal model of Leigh syndrome. Mitochondrion, v. 11, n. 3, p. 413-420, 2011.

STETTNER, Georg M. et al. Spontaneous central apneas occur in the C57BL/6J mouse strain. Respiratory physiology \& neurobiology, v. 160, n. 1, p. 21-27, 2008.

TAKAHASHI, Keiko et al. Chronic intermittent hypoxia-mediated renal sympathetic nerve activation in hypertension and cardiovascular disease. Scientific reports, v. 8, n. 1, p. 1-7, 2018.

TANKERSLEY, Clarke G. et al. Genetic control of differential baseline breathing pattern. Journal of Applied Physiology, v. 82, n. 3, p. 874-881, 1997. 
TANKERSLEY, Clarke G.; ELSTON, Robert C.; SCHNELL, Audrey H.. Genetic determinants of acute hypoxic ventilation: patterns of inheritance in mice. Journal Of Applied Physiology, v. 88, n. 6, p. 2310-2318, 1 jun. 2000.

TANKERSLEY, Clarke G.; RABOLD, Richard; MITZNER, Wayne. Differential lung mechanics are genetically determined in inbred murine strains. Journal of applied physiology, v. 86, n. 6, p. 1764-1769, 1999.

TORDAY, John S. Homeostasis as the mechanism of evolution. Biology, v. 4, n. 3, p. 573-590, 2015.

URBANSKI, Raymond W.; SAPRU, Hreday N.. Evidence for a sympathoexcitatory pathway from the nucleus tractus solitarii to the ventrolateral medullary pressor area. Journal Of The Autonomic Nervous System, v. 23, n. 2, p. 161-174, ago. 1988.

ZHANG, Rongli et al. Hemoglobin $\beta$ Cys93 is essential for cardiovascular function and integrated response to hypoxia. Proceedings of the National Academy of Sciences, v. 112, n. 20, p. 6425-6430, 2015.

ZOCCAL, Daniel B. et al. Increased sympathetic activity in rats submitted to chronic intermittent hypoxia. Experimental physiology, v. 92, n. 1, p. 79-85, 2007.

ZOCCAL, Daniel B. et al. Increased sympathetic outflow in juvenile rats submitted to chronic intermittent hypoxia correlates with enhanced expiratory activity. The Journal of physiology, v. 586, n. 13, p. 3253-3265, 2008.

ZOCCAL, Daniel B. et al. Sympathetic-mediated hypertension of awake juvenile rats submitted to chronic intermittent hypoxia is not linked to baroreflex dysfunction. Experimental physiology, v. 94, n. 9, p. 972-983, 2009a.

ZOCCAL, Daniel B.; MACHADO, Benedito H. Coupling between respiratory and sympathetic activities as a novel mechanism underpinning neurogenic hypertension. Current hypertension reports, v. 13, n. 3, p. 229, 2011.

ZOCCAL, Daniel B.; MACHADO, Benedito H. Sympathetic overactivity coupled with active expiration in rats submitted to chronic intermittent hypoxia. Respiratory physiology \& neurobiology, v. 174, n. 1-2, p. 98-101, 2010.

ZOCCAL, Daniel B; PATON, Julian Fr; MACHADO, Benedito H. Do changes in the coupling between respiratory and sympathetic activities contribute to neurogenic hypertension? Clinical And Experimental Pharmacology And Physiology, v. 36, n. 12, p. 1188-1196, dez. 2009b. 
Apêndice I 
Artigo publicado referente à pesquisa desenvolvida nesta dissertação 


\title{
Changes in the autonomic and respiratory patterns in mice submitted to short-term sustained hypoxia
}

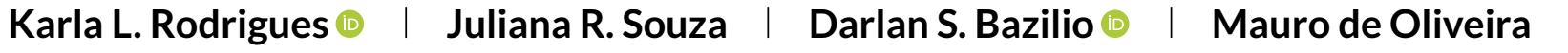

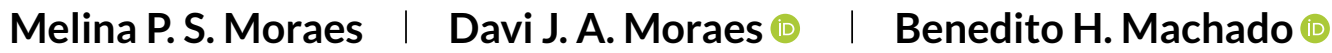

Department of Physiology, School of Medicine of Ribeirão Preto, University of São Paulo, Ribeirão Preto, SP 14049-900, Brazil

Correspondence

Benedito H. Machado, Department of Physiology, School of Medicine of Ribeirão Preto,

University of São Paulo, 14049-900, Ribeirão Preto, SP, Brazil.

Email:bhmachad@fmrp.usp.br

Edited by: Ken O'Halloran

K. L. Rodrigues and J. R. Souza are joint first authors.

Funding information

Fundação de Amparo à Pesquisa do Estado de São Paulo, Grant/Award Numbers:

2018/15957-2, 2019/21916-0; Conselho Nacional de Desenvolvimento Científico e Tecnológico, Grant/Award Number: CNPq303512/2015-6

\begin{abstract}
Short-term sustained hypoxia $(\mathrm{SH})$ in rats induces sympathetic overactivity and hypertension due to changes in sympathetic-respiratory coupling. However, there are no consistent data about the effect of $\mathrm{SH}$ on mice due to the different protocols of hypoxia and difficulties associated with the handling of these rodents under different experimental conditions. In situ recordings of autonomic and respiratory nerves in $\mathrm{SH}$ mice have not been performed yet. Herein, we evaluated the effects of $\mathrm{SH}$ $\left(F_{\mathrm{iO}_{2}}=0.1\right.$ for $\left.24 \mathrm{~h}\right)$ on baseline mean arterial pressure (MAP), heart rate (HR), respiratory frequency $\left(f_{\mathrm{R}}\right)$ and responses to chemoreflex activation in behaving $\mathrm{SH}$ mice. A characterization of changes in cervical vagus (cVN), thoracic sympathetic (tSN), phrenic (PN) and abdominal ( $\mathrm{AbN}$ ) nerves in SH mice using the in situ working heartbrainstem preparation was also performed. SH mice presented normal MAP, significant reduction in baseline $H R$, increase in baseline $f_{R}$, as well as increase in the magnitude of bradycardic response to chemoreflex activation. In in situ preparations, SH mice presented a reduction in PN discharge frequency, and increases in the time of expiration and incidence of late-expiratory bursts in AbN activity. Nerve recordings also indicated a significant increase in cVN activity and a significant reduction in $\mathrm{tSN}$ activity during expiration in $\mathrm{SH}$ mice. These findings make $\mathrm{SH}$ mice an important experimental model for better understanding how changes in the respiratory network may impact on the modulation of vagal control to the upper airways, as well as in the sympathetic activity to the cardiovascular system.

KEYWORDS

active expiration, arterial pressure, C57BL/6 mice, heart rate, inspiration, parasympathetic activity, sustained hypoxia, sympathetic activity
\end{abstract}

\section{1 | INTRODUCTION}

Hypoxia activates peripheral chemoreceptors inducing autonomic and respiratory responses to restore the partial pressure of oxygen $\left(\mathrm{O}_{2}\right)$ in arterial blood (Barros et al., 2002; Costa et al., 2014; Machado,
2001; Machado et al., 2017). Short-term sustained hypoxia (SH) and chronic intermittent hypoxia $(\mathrm{CIH})$ protocols in rats induce changes in sympathetic-respiratory coupling, which seems to be associated with the observed increase in arterial pressure (Moraes et al., 2013, 2014; Zoccal et al., 2008). However, the pattern of autonomic and respiratory 
Apêndice II 
Artigo publicado relacionado ao período de realização do mestrado 


\title{
Distinct cardiovascular and respiratory responses to short-term sustained hypoxia in juvenile Sprague Dawley and Wistar Hannover rats
}

\author{
Darlan S. Bazilio, Karla L. Rodrigues, Davi J.A. Moraes, Benedito H. Machado \\ Department of Physiology, School of Medicine of Ribeirão Preto, University of São Paulo, Ribeirão Preto 14049-900, SP, Brazil
}

\section{A R T I C L E I N F O}

\section{Keywords:}

Sustained hypoxia

Rat strains

Cardiorespiratory parameters

Active expiration

Sympathetic activity

Hypertension

Chemoreflex

\begin{abstract}
A B S T R A C T
Short-term sustained hypoxia (SH) elicits active expiration, augmented late-expiratory (late-E) sympathetic activity, increased arterial pressure and ventilation, and amplified sympathetic and abdominal expiratory responses to chemoreflex activation in rats of the Wistar-Ribeirão Preto (WRP) strain. Herein, we investigated whether SH can differentially affect the cardiovascular and respiratory outcomes of Sprague-Dawley (SD) and Wistar Hannover $(\mathrm{WH})$ rats and compared the results with previous data using WRP rats. For this, we exposed SD and $\mathrm{WH}$ rats to $\mathrm{SH}\left(\mathrm{FiO}_{2}=0.1\right)$ for $24 \mathrm{~h}$ and evaluated arterial pressure, sympathetic activity, and respiratory pattern. SD rats presented increased arterial pressure, respiratory rate and tidal volume, as well as augmented late-E expiratory motor output and increased sympathetic outflow due to post-inspiratory and late-E sympathetic overactivity. WH rats presented reduced changes, suggesting lower responsiveness of this strain to this $\mathrm{SH}$ protocol. The magnitudes of changes in sympathetic and abdominal expiratory motor activities to chemoreflex activation in SD rats were reduced by SH. Pressor responses to chemoreflex activation were shown to be blunted in SD and WH rats after SH. The data are showing that SD, WH, and WRP rat strains exhibit marked differences in their cardiovascular, autonomic and respiratory responses to 24-h SH and draw attention to the importance of rat strain for studies exploring the underlying mechanisms involved in the neuronal changes induced by the experimental model of $\mathrm{SH}$.
\end{abstract}

\section{Introduction}

Maintenance of blood gas homeostasis and optimal tissue perfusion require continuous adjustments in respiratory and cardiovascular functions (Costa et al., 2014; Guyenet and Bayliss, 2015; Machado et al., 2017; Moreira et al., 2011; Zoccal et al., 2009). These adjustments are generated by autonomic and respiratory neural networks in the brainstem, which are modulated by distinct sensorial afferent inputs (Costa et al., 2014; Guyenet, 2014). Upon an acute hypoxic challenge, carotid chemoreceptors are activated to trigger reflex cardiovascular, respiratory and behavioral responses in an attempt to keep $\mathrm{O}_{2}$ partial pressure in arterial blood $\left(\mathrm{PaO}_{2}\right)$ within a physiological range and ensure appropriate tissue perfusion (Costa et al., 2014; Lahiri et al., 2006; Longhurst, 2008; Prabhakar and Semenza, 2015). These responses include sympathoexcitation with increase in arterial pressure, bradycardia, active expiration, tachypnoea, and enhanced alertness and exploration of the environment (Barros et al., 2002; Braga et al., 2007b; Costa et al., 2014; Guyenet, 2000; Machado, 2001). As $\mathrm{PaO}_{2}$ returns to the normal level, the peripheral chemoreflex is deactivated and the cardiorespiratory functions are also adjusted back to normal.

Prolonged exposure to sustained hypoxia ( $\mathrm{SH})$, as experienced by individuals ascending to high altitudes, has been shown to augment sympathetic activity, respiratory rate and tidal volume, leading to increased arterial pressure, heart rate, and pulmonary ventilation (Calbet, 2003; Hackett and Roach, 2001; Hansen and Sander, 2003; Powell, 2007; Powell et al., 2000, 1998; Roach and Hackett, 2001). Adaptations within the central nervous system and within carotid bodies occur during chronic exposure to $\mathrm{SH}$ and may explain not only the timedependent changes in respiratory control during $\mathrm{SH}$ exposure (Forster et al., 1971; Kääb et al., 2005; Powell, 2007; Powell et al., 1998), but also the long-lasting alterations in sympathetic and respiratory activities following return to normoxic conditions (Hansen and Sander, 2003; Powell et al., 1998; Xie et al., 2001). In an experimental model using the Wistar-Ribeirão Preto (WRP) strain of rats, exposure to $24 \mathrm{~h}$ of SH has been demonstrated to lead to marked alterations in autonomic and cardiorespiratory functions both in in vivo experiments and in decerebrated in situ rat preparations. Most prominent alterations include persistent increase in baseline pulmonary ventilation and arterial blood

\footnotetext{
* Corresponding author.

E-mail address: bhmachad@fmrp.usp.br (B.H. Machado).
} 